\title{
Nutritive value of mixed proteins
}

\author{
1. In cereal-based diets for poultry
}

By A. A. WOODHAM aNd P. S. DEANS

Rowett Research Institute, Bucksburn, Aberdeen $A B 2{ }_{9} S B$

(Received I6 May 1975 - Accepted 5 August 1975)

\begin{abstract}
I. Two series of protein feeding-stuffs each consisting of a fish meal, meat-and-bone meal, soya-bean meal, groundnut meal and sunflower-seed meal were analysed for total amino acid composition and evaluated, both individually and combined in all possible pairs, as supplements to cereal-based diets for growing chicks by the total protein efficiency ( $\mathrm{g}$ weight gain/g protein consumed; TPE) procedure. Each pair of feeding-stuffs provided $120 \mathrm{~g}$ supplementary protein $/ \mathrm{kg}$ diet and the diet was made up so that the relative amounts of protein provided by each of the pair of constituents were $(w / w): 120: 0,100: 20,80: 40,60: 60,40: 80,20: 100$ and $0: 120$ respectively, in addition to $60 \mathrm{~g}$ protein $/ \mathrm{kg}$ provided by cereals.

2. In all but one of the twenty pairs of feeding-stuffs studied the mixtures exhibited a marked synergistic effect in that the TPE value was higher than the appropriately weighted mean of the TPE values obtained with the individual components.

3. Neither chemical score ([amount of limiting amino acid/the chick's requirement for the same amino acid] $\times 100$ ) nor essential amino acid index; geometric mean for the ratio, amount of essential amino acid: the chick's requirement for that amino acid, for all ten essential amino acids) calculated from the amino acid composition of the dietary constituents could be used routinely to predict the results of the chick growth test, although chemical score did parallel the TPE values in some instances. In a number of instances, mixtures containing an apparently less favourable amino acid composition than one of the components of the mixture gave a higher TPE value.

4. It seems likely that the relative proportions of a number of amino acids determine the optimum combination of a mixture of proteins. The removal of amino acid deficiencies alone is not sufficient to ensure that a given mixture of proteins produces optimum performance in growing chickens.
\end{abstract}

Ever since the realization that conventional protein feeding-stuffs differed in their amino acid composition, the possibility of supplementary relationships between them has been acknowledged. The nutritional value of various combinations of protein feeding-stuffs have been studied including, for example, sesame-soya bean (Grau \& Almquist, 1944), beef-cereals (Block \& Mitchell, 1946), maize-cowpea (Vigna sinensis) (Bressani \& Scrimshaw, 1961) and sunflower seed-whale meal (Thomas, Martin, Wessels \& Human, 1965). Bressani \& Elias (1968) suggested that when two protein sources of differing nutritive value are mixed the nutritive value of the mixture may either fall precisely on a straight line joining the values of the two components, or there may be a synergistic effect between them resulting in a curve. This curve may either flatten as the composition of the mixture approaches that of the better component, or there may even be combinations which are superior in nutritive value to that of the better component. Such mixtures in which the protein utilization is higher than the appropriately weighted means of the values obtained for the individual components are clearly of special interest because they hold out the possibility of achieving considerable savings of high-quality protein concentrates by replacing 
them with inferior and cheaper materials in the amount needed to give not merely optimum performance, but performance equivalent to, or even better than, that on the better constituent alone.

The present work was planned to study more thoroughly the result of combining various pairs of conventional protein sources along with a constant cereal component under near-practical conditions where the mixture of test concentrates provided two-thirds of the total dietary protein, and cereals provided one-third of the total dietary protein. The total dietary protein level was fixed at $\mathrm{I} 80 \mathrm{~g} / \mathrm{kg}$ in order to avoid the possibility of obliterating the supplementary effects which it was desired to measure.

\section{MATERIALS AND METHODS}

Two series of protein sources (series I and 2), each of five protein concentrates and comprising a white fish meal (FM), a meat-and-bone meal (MM), a soya-bean meal (SB), a sunflower-seed meal (SF) and a groundnut meal (GN), were collected, the first series in 1966 and the second series in 1970. Each of the protein concentrates was purchased from ordinary commercial sources. Cereals for use in the basal diets were purchased similarly and in quantities of $\mathrm{I} t$, each batch being thoroughly mixed before sampling for analysis. More than one batch of the different cereals was needed during the course of the experiments. The amino acid composition of the cereals and concentrates was determined by ion-exchange chromatography and the mixtures evaluated biologically by a chick growth procedure, i.e. the determination of total protein efficiency ( $g$ weight gain/g protein consumed; TPE).

\section{Amino acid analysis}

The method used was based on that of Spackman, Stein \& Moore (1958). Test materials were hydrolysed with $6 \mathrm{M}$-hydrochloric acid, with the flask immersed to just below the internal liquid level in a deep sand-bath. The liquid was boiled gently (sand-bath temperature $110-115^{\circ}$ ) for $18 \mathrm{~h}$ and the amino acids were separated, using a separation programme of $20.5 \mathrm{~h}$, in an AutoAnalyzer (Model NCr; Technicon Instrument Co. Ltd, Basingstoke, Hants) with a $\mathrm{r}_{4} 4 \mathrm{~m} \times 6 \mathrm{~mm}$ column of ChromoBeads B (Technicon Instrument Co. Ltd). Methionine and cystine were estimated in samples oxidized with performic acid (Moore, I963).

For each material at least two hydrolysates were prepared using the unoxidized material and at least another two hydrolysates were prepared using oxidized samples.

\section{Tryptophan}

The method of Spies \& Chambers (r949) was used for the first series of protein concentrates and the modified procedure developed by Matheson (1974) was used for the second series of protein concentrates. The short-comings of the Spies \& Chambers (1949) procedure, which are referred to by Matheson (1974), were apparent when the first series of protein concentrates was being studied and the development of Matheson's (1974) alternative procedure began then. The Matheson (1974) method appears to give somewhat lower values than that of Spies \& Chambers (1949). 


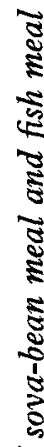

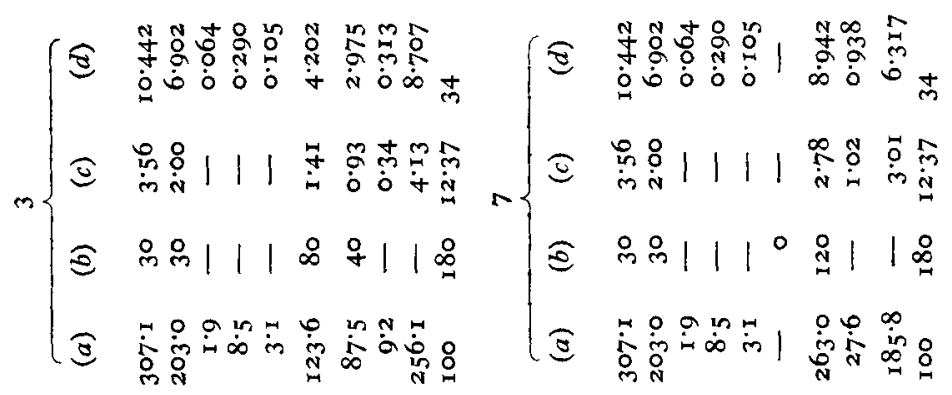

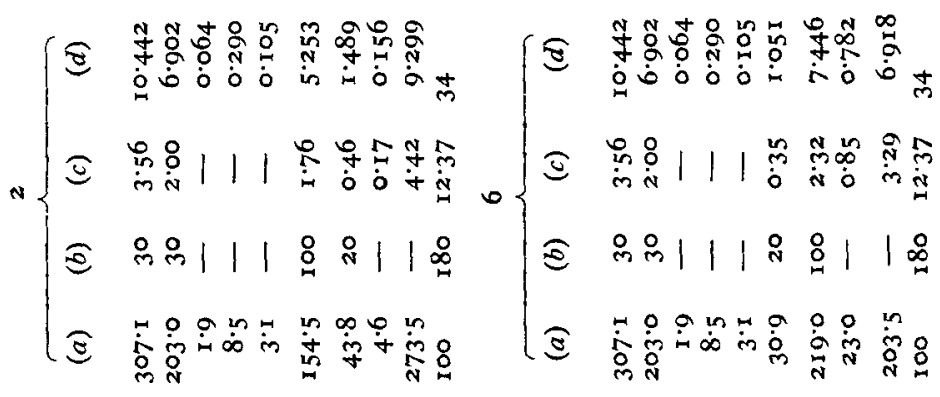

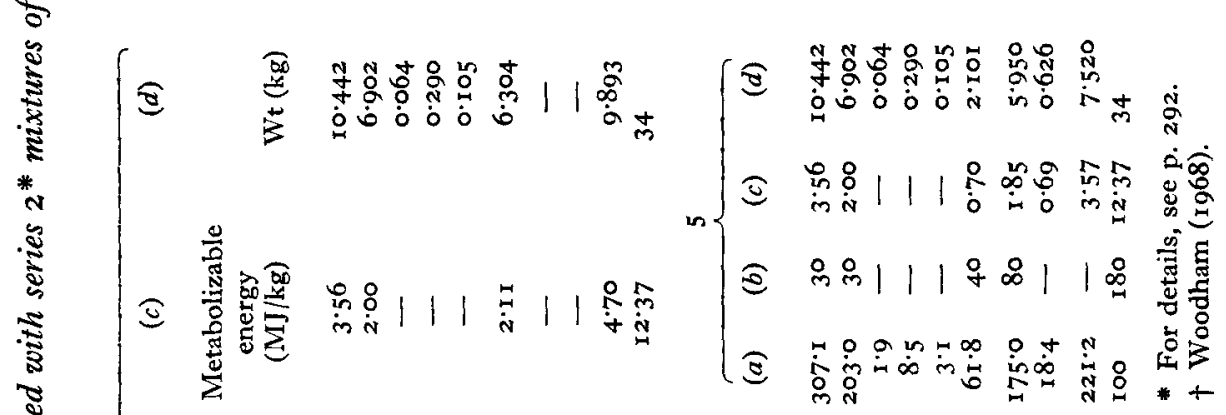

ฐั้

:

5

:

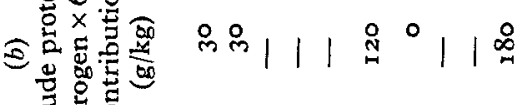

نั

㝴

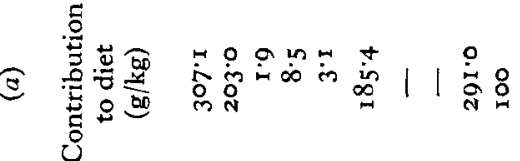

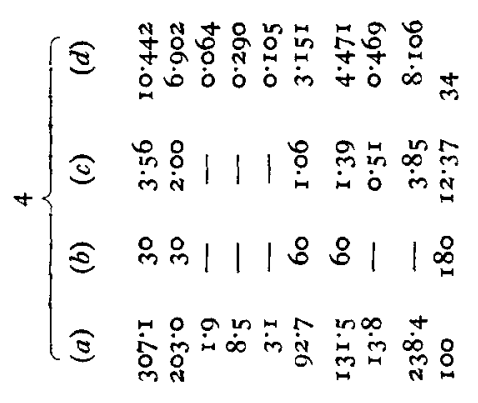

兴

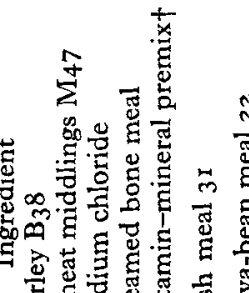

先产若
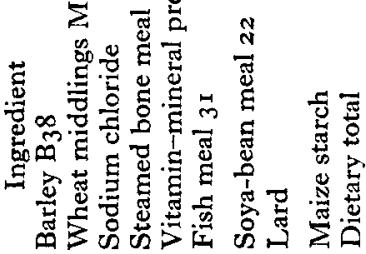


\section{TPE method}

The method used for the evaluation of series I protein concentrates was that described by Woodham ( 1968 ) using Rhode Island Red $\times$ White Leghorn male chicks. For the evaluation of series 2 protein concentrates the method was modified as described by Woodham \& Deans (1973), and male Ross I broiler hybrids were used.

In each experiment five mixtures of protein concentrates in addition to the individual concentrates themselves were evaluated as supplements providing $120 \mathrm{~g}$ crude protein (nitrogen $\times 6.25$ ) $/ \mathrm{kg}$ in diets otherwise consisting of a mixture of barley (B) and wheat middlings (M) which together provided $60 \mathrm{~g}$ protein $/ \mathrm{kg}$ diet, in addition to vitamins and minerals. Diets used in each experiment were made isoenergetic by appropriate additions of maize starch and lard. A specimen set of diets (those used for evaluating FM-SB mixtures in series 2) is given in Table 1 . In calculating the energy contributions by the maize starch and lard used to achieve the isoenergetic diets, values of $16 \cdot 16$ and $36 \cdot 80 \mathrm{MJ} / \mathrm{kg}$ were used for maize starch and lard respectively.

As an example, a series of FM-SB mixtures contained B protein $(3 \circ \mathrm{g} / \mathrm{kg})$ and $M$ protein $(3 \circ \mathrm{g} / \mathrm{kg})$, the protein supplements providing $\mathrm{I} 20 \mathrm{~g}$ protein $/ \mathrm{kg}$, the relative amounts of the components of the mixtures being respectively (w/w): FM I20, FMSB 100:20, FM-SB 80:40, FM-SB 60:60, FM-SB 40:80, FM-SB 20:100, SB 120. Each treatment was tested on four groups of chicks, each consisting of six chicks, kept in one house, and the complete trial was repeated with groups of chicks kept in a second house. The T'PE values for the mixtures are given as the means of the eight individual values.

\section{RESULTS}

The $\mathrm{N}$ content and the total amino acid composition of the basal cereals used in the testing of both series of protein concentrates are given in Table 2 , and the composition of all protein concentrates used is shown in Table 3. Three different cereal combinations were used with series I protein concentrates and two cereal combinations were used with series 2 protein concentrates, and their respective contributions of essential amino acids are tabulated in Table 7 together with the contributions made by the protein concentrates. The third cereal-basal diet used with series 2 protein concentrates consisted of B only and this contributed $60 \mathrm{~g}$ protein $/ \mathrm{kg}$ diet. Each of the other basal mixtures contained equal amounts of $B$ and $M$ protein, each component contributing $30 \mathrm{~g}$ protein $/ \mathrm{kg}$ diet. Each of the protein concentrates contributed $120 \mathrm{~g}$ protein $/ \mathrm{kg}$ diet.

The basal cereals used for evaluating each of the protein-concentrate mixtures were as follows:

\begin{tabular}{lll} 
& Cereal mixture & \multicolumn{1}{c}{ Protein-concentrate mixtures } \\
series I & $B_{986-M 988}$ & MM-GN, FM-GN, FM-MM, SF-MM, SB-MM \\
& B2-M $_{3}$ & SB-GN, SB-SF, SF-FM, SF-GN \\
B986 & SB-FM \\
series 2 & B2O-M21 $_{28}$ & SF-GN, MM-GN, SF-MM, SB-MM, SB-GN, SB-SF \\
& $B_{3} 8-M_{47}$ & FM-GN, FM-MM, SF-FM, SB-FM
\end{tabular}


Table 2. Amino acid composition (g/kg crude protein (nitrogen $\times 6 \cdot 25)$ ) of basal cereals in diets given to growing chicks

Series of protein concentrates* ...

Cereal* $\ldots$

Amino acid

Aspartic acid

Threonine

Serine

Glutamic acid

Proline

Glycine

Alanine

Valine

Cystine

Methionine

Isoleucine

Leucine

Tyrosine

Phenylalanine

Lysine

Histidine

Arginine

Tryptophan

Recovery of amino

acid-N (\% total

$\mathrm{N}$ analysed)

Total $\mathbf{N}$ in sample (g/kg)

\begin{tabular}{|c|c|c|c|c|c|c|c|}
\hline \multicolumn{4}{|c|}{ I } & \multicolumn{4}{|c|}{2} \\
\hline \multicolumn{2}{|c|}{ Barley } & \multicolumn{2}{|c|}{$\begin{array}{l}\text { Wheat } \\
\text { middlings }\end{array}$} & \multicolumn{2}{|c|}{ Barley } & \multicolumn{2}{|c|}{$\begin{array}{l}\text { Wheat } \\
\text { middlings }\end{array}$} \\
\hline $\mathrm{B}_{2}$ & B986 & $\mathrm{M}_{3}$ & $\mathrm{M}_{9} 88$ & B2o & $\mathrm{B}_{3} 8$ & $\mathrm{M}_{21}$ & $\mathrm{M}_{47}$ \\
\hline 56 & 59 & 60 & 75 & 63 & 57 & 60 & 63 \\
\hline 27 & 35 & 26 & 34 & $3^{8}$ & 31 & 32 & 30 \\
\hline $3 I$ & 39 & 35 & 44 & 45 & 40 & 40 & 40 \\
\hline 223 & 230 & 191 & 213 & 210 & 210 & 207 & 184 \\
\hline 123 & 130 & 73 & 73 & 94 & II 5 & 75 & 67 \\
\hline 42 & 42 & 47 & 52 & 48 & 38 & 53 & 42 \\
\hline 42 & 44 & 44 & $5 \mathrm{I}$ & 50 & 37 & 44 & 41 \\
\hline 46 & 56 & 43 & 52 & 57 & 39 & 45 & 32 \\
\hline 25 & 27 & 23 & $2 I$ & 31 & 26 & 19 & $2 I$ \\
\hline 14 & 22 & 22 & 15 & 17 & 26 & 17 & 12 \\
\hline $\begin{array}{l}34 \\
66\end{array}$ & $\begin{array}{l}40 \\
76\end{array}$ & $\begin{array}{l}32 \\
6 I\end{array}$ & $\begin{array}{l}35 \\
65\end{array}$ & $\begin{array}{l}39 \\
78\end{array}$ & $\begin{array}{l}27 \\
63\end{array}$ & $\begin{array}{l}34 \\
6 I\end{array}$ & $\begin{array}{l}22 \\
52\end{array}$ \\
\hline 34 & 25 & $3 \mathrm{I}$ & 30 & 38 & 32 & 30 & 27 \\
\hline 53 & 58 & $4 I$ & 42 & $5^{2}$ & 45 & 39 & 34 \\
\hline 38 & 39 & 43 & 43 & 46 & 34 & 39 & 35 \\
\hline I9 & 23 & 24 & 27 & 23 & 18 & 23 & 20 \\
\hline 46 & 54 & 65 & 72 & 59 & 47 & $5^{8}$ & $5^{6}$ \\
\hline ND & 14 & ND & 18 & ND & To & ND & ND \\
\hline $91 \cdot 9$ & IOI' 3 & $86 \cdot I$ & $96 \cdot 2$ & $98 \cdot 8$ & $88 \cdot 5$ & $87 \cdot 6$ & $77 \cdot 8$ \\
\hline 16.6 & 154 & $22 \cdot 8$ & $26 \cdot I$ & $12 \cdot 6$ & 15.6 & $26 \cdot 9$ & $23 \cdot 6$ \\
\hline
\end{tabular}

ND, not determined.

* For details, see p. 292.

The values obtained for body-weight gain, protein intake and TPE are tabulated in Table 4 (series I) and Table 5 (series 2 ) and the TPE values for series I and 2 are shown together in Fig. I. Although the set of mixtures for each pair of protein concentrates was made isoenergetic, because of the variety of protein sources and the changing basal cereals, it was not possible to maintain a single energy level throughout either series. Consequently it will be observed that different TPE values were sometimes obtained for the same concentrate when tested in different experiments. Results for series 2 in which broiler hybrid chicks were used are understandably higher than those for series I but the general pattern of the results for series I and 2 was remarkably similar. In common with other biological protein-quality tests such as the protein efficiency ratio (PER) and the net protein utilization procedures, the TPE may be influenced by extreme differences in food intake. Our experience coincides with that of Campbell (1963) regarding PER in that the differences found under carefullycontrolled conditions were not so great as to invalidate the comparisons. In four separate estimates of TPE for a single sample of GN for example, protein intake (g/bird per d), weight gain (g) and TPE were respectively: $4.63,8 \cdot 27,1 \cdot 79 ; 5.18$, 
Table 3. Amino acid composition ( $\mathrm{g} / \mathrm{kg}$ crude protein (nitrogen $\times 6 \cdot 25)$ ) of protein concentrates in diets given to growing chicks

Series of protein concentrates*

Protein concentrate ...

Amino acid

Aspartic acid

Threonine

Serine

Glutamic acid

Proline

Glycine

Alanine

Valine

Cystine

Methionine

Isoleucine

Leucine

Tyrosine

Phenylalanine

Lysine

Histidine

Arginine

Tryptophan

Recovery of amino

acid-N (\% total

$\mathrm{N}$ analysed)

Total $\mathrm{N}$ in sample (g/kg)

\begin{tabular}{|c|c|c|c|c|}
\hline FM & $\mathrm{MM}$ & GN & SB & $\mathrm{SF}$ \\
\hline$P_{968}$ & $\mathrm{P}_{977}$ & $\mathrm{P}_{971}$ & $\mathrm{P}_{978}$ & $P_{979}$ \\
\hline $9 \mathrm{I}$ & 75 & I I 5 & 119 & 95 \\
\hline 42 & $3 \mathrm{I}$ & 30 & 39 & $3^{8}$ \\
\hline 47 & 37 & $5^{1}$ & 50 & 45 \\
\hline I33 & 122 & 194 & $17^{8}$ & 205 \\
\hline $5^{6}$ & 96 & 48 & 54 & $4^{6}$ \\
\hline 95 & I 36 & 59 & $4^{\circ}$ & 55 \\
\hline 69 & 80 & $4 I$ & 42 & 46 \\
\hline 48 & 46 & 44 & 47 & 46 \\
\hline I I 8 & 6 & 14.1 & $15 \cdot 1$ & I 8.4 \\
\hline 25 & 6 & 10 & 12 & 24 \\
\hline 39 & 26 & $3^{6}$ & 42 & 39 \\
\hline 67 & 58 & 66 & 74 & 62 \\
\hline 29 & I 8 & $4 I$ & 34 & 25 \\
\hline 37 & 35 & 53 & 54 & 43 \\
\hline 74 & 49 & 37 & 61 & 35 \\
\hline 19 & 18 & 25 & 26 & 24 \\
\hline 69 & 69 & 121 & 75 & 87 \\
\hline 14 & 12 & I I & 19 & 18 \\
\hline
\end{tabular}

$96 \cdot 6 \quad 92 \cdot 0 \quad 99 \cdot 6 \quad 98 \cdot 1 \quad 95 \cdot 1$

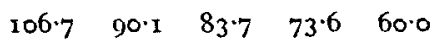

\begin{tabular}{|c|c|c|c|c|}
\hline FM & $\mathrm{MM}$ & GN & SB & SF \\
\hline 31 & 27 & 26 & 22 & 29 \\
\hline 94 & 70 & 103 & II 5 & 9I \\
\hline 42 & 29 & 26 & 41 & 36 \\
\hline 51 & 37 & 44 & 55 & 43 \\
\hline I35 & 113 & 169 & 181 & 197 \\
\hline 69 & 85 & $4 I$ & 49 & 60 \\
\hline 86 & 130 & 52 & 46 & 57 \\
\hline 67 & 73 & $3^{8}$ & 50 & 42 \\
\hline $5 \mathrm{I}$ & 42 & $4 I$ & 55 & 50 \\
\hline 10 & 7 & 13 & I 5 & 19 \\
\hline I 8 & 12 & 7 & 9 & 24 \\
\hline 42 & 25 & 34 & 52 & 43 \\
\hline $7 x$ & $5^{8}$ & $6 I$ & 82 & 62 \\
\hline 34 & 21 & 39 & 38 & 27 \\
\hline $4^{\circ}$ & 34 & $5^{\circ}$ & 53 & 48 \\
\hline 73 & 52 & 32 & 69 & 37 \\
\hline 23 & 20 & 22 & 27 & 26 \\
\hline 69 & $7 I$ & 100 & 75 & 85 \\
\hline 9 & 6 & 8 & 12 & 12 \\
\hline
\end{tabular}

$\begin{array}{lllll}98 \cdot 4 & 88 \cdot 5 & 88 \cdot 0 & 99 \cdot 4 & 95 \cdot 9\end{array}$

$\begin{array}{lllll}103 \cdot 6 & 85 \cdot 1 & 72 \cdot 7 & 73 \cdot 1 & 63 \cdot 7\end{array}$

FM, fish meal; MM, meat meal; GN, groundnut meal; SB, soya-bean meal; SF, sunflower-seed meal. * For details, see p. 292.

$9 \cdot 31, x \cdot 80 ; 4.00,6 \cdot 98,1.75 ; 4.04,7 \cdot 15,1 \cdot 77$. We have no evidence to suggest that the level of supplementary protein ( $120 \mathrm{~g} / \mathrm{kg}$ diet) used in the TPE experiments might contribute a dangerously high level of minerals when normal FM and MM are tested (Woodham, 1968). The curves in Figs $1-3$ are based on the plotted values and fitted by eye.

In all but one of the twenty sets of values the curved response line indicated an advantage from combining the pairs of protein concentrates. The exception was the values for SB-GN combinations (series I) where the points were on a straight line. The values for SB-GN combinations in series 2 were on a line which was only slightly curved and it would seem from this result that little advantage is to be expected from combining SB with GN. In the other sets there was clear evidence that combinations were advantageous, but the proportions of the two protein concentrate components which gave the maximum response differed considerably. In the instance of MM-GN combinations, for example, the optimum amounts would seem to be approximately $50: 50(\mathrm{w} / \mathrm{w})$ for both series, whereas for SB-MM combinations optimum protein utilization was achieved when the SB comprised approximately $75 \%$ of the mixture. With FM-GN and FM-MM combinations a much more decisive advantage was indicated in one series than in the other though in both 
Table 4. Series I protein concentrates*. Intake of crude protein (nitrogen $\times 6 \cdot 25)(\mathrm{g} /$ bird per $d$ ), weight gain ( $g /$ bird per $d$ ), and total protein efficiency ( $g$ weight gain/g protein consumed; TPE) for RIR $\times W L$ chicks given cereal-based diets supplemented with pairs of protein concentrates $\left(P C_{1}, P C_{2}\right)$ mixed in varying proportions to contribute $120 \mathrm{~g}$ protein $/ \mathrm{kg}$ diet

\begin{tabular}{|c|c|c|c|c|c|c|c|c|c|}
\hline & \multirow[b]{2}{*}{$\mathrm{PC}_{1}-\mathrm{PC}_{2}$} & \multirow[b]{2}{*}{ Basal cereals* } & \multicolumn{7}{|c|}{ Relative amounts of $\mathrm{PC}_{1}-\mathrm{PC} 2(\mathrm{w} / \mathrm{w})$} \\
\hline & & & $120: 0$ & $100: 20$ & $80: 40$ & $60: 60$ & $40: 80$ & $20: 100$ & $0: 120$ \\
\hline $\begin{array}{l}\text { Crude protein intake } \\
\text { Wt gain } \\
\text { TPE }\end{array}$ & MM-GN & & $\begin{array}{l}4 \cdot 05 \\
7 \cdot 05 \\
1 \cdot 74\end{array}$ & $\begin{array}{l}4 \cdot 67 \\
8 \cdot 75 \\
x \cdot 87\end{array}$ & $\begin{array}{l}4 \cdot 77 \\
9 \cdot 12 \\
I \cdot 91\end{array}$ & $\begin{array}{l}5 \cdot 01 \\
9 \cdot 98 \\
x \cdot 99\end{array}$ & $\begin{array}{l}4 \cdot 92 \\
9 \cdot 64 \\
I \cdot 96\end{array}$ & $\begin{array}{l}4 \cdot 80 \\
9 \cdot 07 \\
1 \cdot 89\end{array}$ & $\begin{array}{l}4 \cdot 63 \\
8 \cdot 27 \\
I \cdot 79\end{array}$ \\
\hline $\begin{array}{l}\text { Crude protein intake } \\
\text { Wt gain } \\
\text { TPE }\end{array}$ & FM-GN & & $\begin{array}{r}5 \cdot 18 \\
12 \cdot 65 \\
2 \cdot 44\end{array}$ & $\begin{array}{r}5 \cdot 41 \\
12 \cdot 84 \\
2 \cdot 38\end{array}$ & $\begin{array}{r}5 \cdot 38 \\
+2 \cdot 69 \\
2 \cdot 36\end{array}$ & $\begin{array}{r}5 \cdot 46 \\
12 \cdot 04 \\
2 \cdot 21\end{array}$ & $\begin{array}{r}5 \cdot 38 \\
I 1 \cdot 72 \\
2 \cdot 18\end{array}$ & $\begin{array}{r}5 \cdot 50 \\
10 \cdot 93 \\
1 \cdot 99\end{array}$ & $\begin{array}{l}5 \cdot 18 \\
9 \cdot 3 I \\
I \cdot 80\end{array}$ \\
\hline $\begin{array}{l}\text { Crude protein intake } \\
\text { Wt gain } \\
\text { TPE }\end{array}$ & FM-MM & $\mathrm{B}_{9} 86-\mathrm{M}_{9} 88$ & $\begin{array}{r}4.83 \\
11.80 \\
2.44\end{array}$ & $\begin{array}{r}4 \cdot 78 \\
I I \cdot 93 \\
2 \cdot 50\end{array}$ & $\begin{array}{r}4 \cdot 77 \\
\text { II } 44 \\
2 \cdot 40\end{array}$ & $\begin{array}{r}4.65 \\
10.84 \\
2.33\end{array}$ & $\begin{array}{l}4 \cdot 39 \\
9 \cdot 27 \\
2 \cdot 11\end{array}$ & $\begin{array}{l}4 \cdot 14 \\
7 \cdot 77 \\
1 \cdot 87\end{array}$ & $\begin{array}{l}3.69 \\
5.99 \\
1.62\end{array}$ \\
\hline $\begin{array}{l}\text { Crude protein intake } \\
\text { Wt gain } \\
\text { TPE }\end{array}$ & SF-MM & & $\begin{array}{r}5 \cdot 11 \\
10 \cdot 47 \\
2 \cdot 05\end{array}$ & $\begin{array}{r}5 \cdot 00 \\
10 \cdot 76 \\
2 \cdot 15\end{array}$ & $\begin{array}{r}5 \cdot 19 \\
\text { II } 53 \\
2 \cdot 22\end{array}$ & $\begin{array}{r}4 \cdot 98 \\
10.70 \\
2 \cdot 15\end{array}$ & $\begin{array}{l}4.70 \\
9.46 \\
2.01\end{array}$ & $\begin{array}{l}4 \cdot 29 \\
7 \cdot 80 \\
I \cdot 82\end{array}$ & $\begin{array}{l}3 \cdot 56 \\
5 \cdot 25 \\
1 \cdot 47\end{array}$ \\
\hline $\begin{array}{l}\text { Crude protein intake } \\
\text { Wt gain } \\
\text { TPE }\end{array}$ & SB-MM & & $\begin{array}{l}4 \cdot 56 \\
8 \cdot 84 \\
I \cdot 94\end{array}$ & $\begin{array}{r}4 \cdot 99 \\
10 \cdot 16 \\
2 \cdot 04\end{array}$ & $\begin{array}{r}4.93 \\
10.07 \\
2.04\end{array}$ & $\begin{array}{l}4 \cdot 89 \\
9 \cdot 71 \\
1 \cdot 98\end{array}$ & $\begin{array}{l}4 \cdot 66 \\
8 \cdot 6 r \\
I \cdot 85\end{array}$ & $\begin{array}{l}4 \cdot 08 \\
6 \cdot 81 \\
1 \cdot 67\end{array}$ & $\begin{array}{l}3 \cdot 56 \\
5 \cdot 16 \\
1 \cdot 44\end{array}$ \\
\hline $\begin{array}{l}\text { Crude protein intake } \\
\text { Wt gain } \\
\text { TPE }\end{array}$ & SB-GN & & $\begin{array}{l}4 \cdot 32 \\
8 \cdot 48 \\
I \cdot 96\end{array}$ & $\begin{array}{l}4 \cdot 27 \\
8 \cdot 28 \\
I \cdot 94\end{array}$ & $\begin{array}{l}4 \cdot 27 \\
8 \cdot 03 \\
I \cdot 88\end{array}$ & $\begin{array}{l}4 \cdot 14 \\
7 \cdot 77 \\
1 \cdot 87\end{array}$ & $\begin{array}{l}4 \cdot 18 \\
7 \cdot 68 \\
I \cdot 84\end{array}$ & $\begin{array}{l}4 \cdot 12 \\
7 \cdot 53 \\
I \cdot 82\end{array}$ & $\begin{array}{l}4 \cdot 00 \\
6 \cdot 98 \\
1 \cdot 75\end{array}$ \\
\hline $\begin{array}{l}\text { Crude protein intake } \\
\text { Wt gain } \\
\text { TPE }\end{array}$ & SB-SF & & $\begin{array}{l}4 \cdot 30 \\
8 \cdot 12 \\
1 \cdot 90\end{array}$ & $\begin{array}{l}4 \cdot 46 \\
8.40 \\
1 \cdot 89\end{array}$ & $\begin{array}{l}4 \cdot 44 \\
8 \cdot 74 \\
I \cdot 97\end{array}$ & $\begin{array}{l}4 \cdot 36 \\
8 \cdot 48 \\
I \cdot 94\end{array}$ & $\begin{array}{l}4 \cdot 44 \\
8 \cdot 47 \\
I \cdot 91\end{array}$ & $\begin{array}{l}4 \cdot 46 \\
8 \cdot 37 \\
I \cdot 88\end{array}$ & $\begin{array}{l}4 \cdot 43 \\
8 \cdot 15 \\
1 \cdot 84\end{array}$ \\
\hline $\begin{array}{l}\text { Crude protein intake } \\
\text { Wt gain } \\
\text { TPE }\end{array}$ & SF-FM & & $\begin{array}{l}4 \cdot 58 \\
8 \cdot 21 \\
I \cdot 80\end{array}$ & $\begin{array}{r}4 \cdot 89 \\
10 \cdot 46 \\
2 \cdot 14\end{array}$ & $\begin{array}{r}5 \cdot 38 \\
12 \cdot 47 \\
2 \cdot 32\end{array}$ & $\begin{array}{r}5.15 \\
12.66 \\
2.46\end{array}$ & $\begin{array}{r}5.04 \\
12.57 \\
2.49\end{array}$ & $\begin{array}{r}5 \cdot 05 \\
12 \cdot 54 \\
2 \cdot 48\end{array}$ & $\begin{array}{r}5.05 \\
12.45 \\
2.47\end{array}$ \\
\hline $\begin{array}{l}\text { Crude protein intake } \\
\text { Wt gain } \\
\text { TPE }\end{array}$ & SF-GN & & $\begin{array}{l}4 \cdot 13 \\
7 \cdot 39 \\
1 \cdot 79\end{array}$ & $\begin{array}{l}4 \cdot 19 \\
7 \cdot 53 \\
1 \cdot 80\end{array}$ & $\begin{array}{l}4 \cdot 37 \\
8 \cdot 26 \\
I \cdot 89\end{array}$ & $\begin{array}{l}4 \cdot 48 \\
8 \cdot 49 \\
I \cdot 89\end{array}$ & $\begin{array}{l}4 \cdot 35 \\
8 \cdot 09 \\
r \cdot 86\end{array}$ & $\begin{array}{l}4 \cdot 33 \\
7 \cdot 83 \\
1 \cdot 81\end{array}$ & $\begin{array}{l}4 \cdot 04 \\
7 \cdot 15 \\
1 \cdot 77\end{array}$ \\
\hline $\begin{array}{l}\text { Crude protein intake } \\
\text { Wt gain } \\
\text { TPE }\end{array}$ & SB-FM & $\mathrm{Bg} 86$ & $\begin{array}{r}5 \cdot 40 \\
11 \cdot 76 \\
2 \cdot 18\end{array}$ & $\begin{array}{r}5 \cdot 39 \\
12 \cdot 33 \\
2 \cdot 34\end{array}$ & $\begin{array}{r}5 \cdot 27 \\
12 \cdot 70 \\
2 \cdot 41\end{array}$ & $\begin{array}{r}5 \cdot 17 \\
12 \cdot 46 \\
2 \cdot 41\end{array}$ & $\begin{array}{r}5.25 \\
12 \cdot 88 \\
2 \cdot 47\end{array}$ & $\begin{array}{r}5.08 \\
12.72 \\
2.50\end{array}$ & $\begin{array}{r}5 \cdot 00 \\
12 \cdot 26 \\
2 \cdot 46\end{array}$ \\
\hline
\end{tabular}

RIR, Rhode Island Red; WL, White Leghorn; MM, meat meal; GN, groundnut meal; FM, fish meal; SF, sunflower-seed meal; SB, soya-bean meal; $B$, barley; $M$, wheat middlings.

* For details, see p. 293 and Tables 2 and 3.

instances it appeared from the results with both series that it was advantageous to combine a proportion of the poorer-quality concentrate, GN or MM, with FM, the latter always being the major constituent.

\section{DISCUSSION}

The results provided useful information regarding the possibilities of sparing good-quality protein concentrates such as FM or SB by inferior, and perhaps cheaper ones. SF may replace half the FM, for example, without any deterioration in chick growth and protein utilization, and even GN can effect a quite considerable saving. 
Table 5. Series 2 protein concentrates*. Intake of crude protein (nitrogen $\times 6.25)(\mathrm{g} /$ bird per $d$ ), weight gain ( $g /$ bird per $d$ ) and total protein efficiency ( $g$ weight gain/g protein consumed; TPE) for Ross I broiler hybrid chicks given cereal-based diets $\dagger$ supplemented with pairs of protein concentrates $\left(P C_{1}, P C_{2}\right)$ mixed in varying proportions to contribute 1 $20 \mathrm{~g}$ protein/kg diet

\begin{tabular}{|c|c|c|c|c|c|c|c|c|c|}
\hline & & & & Relat & $\mathrm{m}$ & ints o & $\mathrm{r}-$ & w) & \\
\hline & $\mathrm{PC}_{1}-\mathrm{PC}_{2}$ & Basal cereals & $120: 0$ & $100: 20$ & $80: 40$ & $60: 60$ & $40: 80$ & $20: 100$ & $0: 120$ \\
\hline $\begin{array}{l}\text { Crude protein intake } \\
\text { Wt gain } \\
\text { TPE }\end{array}$ & SF-GN & & $\begin{array}{r}7 \cdot 30 \\
14 \cdot 17 \\
1 \cdot 94\end{array}$ & $\begin{array}{r}7 \cdot 20 \\
15 \cdot 94 \\
2 \cdot 21\end{array}$ & $\begin{array}{r}7 \cdot 20 \\
16 \cdot 48 \\
2 \cdot 29\end{array}$ & $\begin{array}{r}6.64 \\
14.87 \\
2 \cdot 24\end{array}$ & $\begin{array}{r}6.68 \\
14.79 \\
2.21\end{array}$ & $\begin{array}{r}6 \cdot 39 \\
13 \cdot 71 \\
2 \cdot 15\end{array}$ & $\begin{array}{r}6 \cdot 48 \\
13 \cdot 83 \\
2 \cdot 13\end{array}$ \\
\hline $\begin{array}{l}\text { Crude protein intake } \\
\text { Wt gain } \\
\text { TPE }\end{array}$ & $\mathrm{MM}-\mathrm{GN}$ & & $\begin{array}{r}6.07 \\
12.68 \\
2.09\end{array}$ & $\begin{array}{r}6 \cdot 51 \\
14 \cdot 17 \\
2 \cdot 18\end{array}$ & $\begin{array}{r}6 \cdot 90 \\
15 \cdot 64 \\
2 \cdot 31\end{array}$ & $\begin{array}{r}7 \cdot 15 \\
16 \cdot 70 \\
2 \cdot 33\end{array}$ & $\begin{array}{r}6 \cdot 92 \\
x 6 \cdot 10 \\
2 \cdot 33\end{array}$ & $\begin{array}{r}6 \cdot 77 \\
15 \cdot 24 \\
2 \cdot 25\end{array}$ & $\begin{array}{r}6 \cdot 39 \\
13 \cdot 71 \\
2 \cdot 15\end{array}$ \\
\hline $\begin{array}{l}\text { Crude protein intake } \\
\text { Wt gain } \\
\text { TPE }\end{array}$ & SF-MM & & $\begin{array}{r}7.71 \\
18.69 \\
2.42\end{array}$ & $\begin{array}{r}7 \cdot 40 \\
18 \cdot 42 \\
2 \cdot 49\end{array}$ & $\begin{array}{r}7 \cdot 40 \\
18 \cdot 13 \\
2 \cdot 45\end{array}$ & $\begin{array}{r}7 \cdot 49 \\
17 \cdot 88 \\
2 \cdot 39\end{array}$ & $\begin{array}{r}7 \cdot 25 \\
17 \cdot 31 \\
2 \cdot 39\end{array}$ & $\begin{array}{r}7 \cdot 05 \\
16 \cdot 18 \\
2 \cdot 29\end{array}$ & $\begin{array}{r}6 \cdot 26 \\
13 \cdot 49 \\
.2 \cdot 15\end{array}$ \\
\hline $\begin{array}{l}\text { Crude protein intake } \\
\text { Wt gain } \\
\text { TPE }\end{array}$ & SB-MM & & $\begin{array}{r}7 \cdot 58 \\
20 \cdot 74 \\
2 \cdot 74\end{array}$ & $\begin{array}{r}7 \cdot 57 \\
21 \cdot 42 \\
2 \cdot 84\end{array}$ & $\begin{array}{r}7 \cdot 44 \\
20 \cdot 89 \\
2 \cdot 81\end{array}$ & $\begin{array}{r}7.40 \\
19.88 \\
2.69\end{array}$ & $\begin{array}{r}7.04 \\
18.04 \\
2.57\end{array}$ & $\begin{array}{r}6 \cdot 36 \\
\times 5 \cdot 13 \\
2 \cdot 38\end{array}$ & $\begin{array}{r}5 \cdot 58 \\
12 \cdot 36 \\
2 \cdot 22\end{array}$ \\
\hline $\begin{array}{l}\text { Crude protein intake } \\
\text { Wt gain } \\
\text { TPE }\end{array}$ & SB-GN & & $\begin{array}{r}8 \cdot 39 \\
22 \cdot 54 \\
2 \cdot 69\end{array}$ & $\begin{array}{r}8 \cdot 26 \\
2 r \cdot 73 \\
2 \cdot 63\end{array}$ & $\begin{array}{r}8 \cdot 15 \\
20 \cdot 82 \\
2 \cdot 55\end{array}$ & $\begin{array}{r}8 \cdot 00 \\
20 \cdot 31 \\
2 \cdot 54\end{array}$ & $\begin{array}{r}7 \cdot 76 \\
18 \cdot 98 \\
2 \cdot 44\end{array}$ & $\begin{array}{r}7 \cdot 49 \\
17 \cdot 42 \\
2 \cdot 32\end{array}$ & $\begin{array}{r}6.64 \\
14.10 \\
2.12\end{array}$ \\
\hline $\begin{array}{l}\text { Crude protein intake } \\
\text { Wt gain } \\
\text { TPE }\end{array}$ & SB-SF & & $\begin{array}{r}7 \cdot 71 \\
19.73 \\
2 \cdot 56\end{array}$ & $\begin{array}{r}8 \cdot 05 \\
21 \cdot 76 \\
2 \cdot 70\end{array}$ & $\begin{array}{r}8 \cdot 25 \\
22 \cdot 57 \\
2 \cdot 74\end{array}$ & $\begin{array}{r}7 \cdot 96 \\
21 \cdot 26 \\
2 \cdot 67\end{array}$ & $\begin{array}{r}7 \cdot 76 \\
20 \cdot 69 \\
2 \cdot 67\end{array}$ & $\begin{array}{r}7 \cdot 49 \\
\times 8 \cdot 83 \\
2 \cdot 51\end{array}$ & $\begin{array}{r}6 \cdot 96 \\
16 \cdot 20 \\
2 \cdot 33\end{array}$ \\
\hline $\begin{array}{l}\text { Crude protein intake } \\
\text { Wt gain } \\
\text { TPE }\end{array}$ & $\mathrm{FM}-\mathrm{GN}$ & & $\begin{array}{r}6 \cdot 83 \\
19 \cdot 73 \\
2 \cdot 88\end{array}$ & $\begin{array}{r}7 \cdot 07 \\
21 \cdot 42 \\
3 \cdot 02\end{array}$ & $\begin{array}{r}7.33 \\
22.24 \\
3.03\end{array}$ & $\begin{array}{r}7 \cdot 26 \\
21 \cdot 32 \\
2 \cdot 93\end{array}$ & $\begin{array}{r}7 \cdot 02 \\
19.08 \\
2 \cdot 71\end{array}$ & $\begin{array}{r}6 \cdot 51 \\
16 \cdot 23 \\
2 \cdot 49\end{array}$ & $\begin{array}{r}5.80 \\
12.11 \\
2.09\end{array}$ \\
\hline $\begin{array}{l}\text { Crude protein intake } \\
\text { Wt gain } \\
\text { TPE }\end{array}$ & $F M-M M$ & & $\begin{array}{r}7 \cdot 41 \\
22 \cdot 02 \\
3 \cdot 01\end{array}$ & $\begin{array}{r}7 \cdot 39 \\
21 \cdot 52 \\
2 \cdot 95\end{array}$ & $\begin{array}{r}7 \cdot 32 \\
20 \cdot 3^{8} \\
2 \cdot 75\end{array}$ & $\begin{array}{r}7 \cdot 28 \\
\times 9 \cdot 53 \\
2 \cdot 68\end{array}$ & $\begin{array}{r}7.01 \\
17.55 \\
2.54\end{array}$ & $\begin{array}{r}6 \cdot 65 \\
15 \cdot 58 \\
2 \cdot 34\end{array}$ & $\begin{array}{r}6.02 \\
12.66 \\
2.08\end{array}$ \\
\hline $\begin{array}{l}\text { Crude protein intake } \\
\text { Wt gain } \\
\text { TPE }\end{array}$ & $S F-F M$ & $B_{3} 8-M_{47}$ & $\begin{array}{r}7 \cdot 39 \\
16 \cdot 76 \\
2 \cdot 27\end{array}$ & $\begin{array}{r}8 \cdot 02 \\
20 \cdot 83 \\
2 \cdot 59\end{array}$ & $\begin{array}{r}8 \cdot 09 \\
22 \cdot 64 \\
2 \cdot 80\end{array}$ & $\begin{array}{r}8 \cdot 15 \\
24 \cdot 02 \\
2 \cdot 94\end{array}$ & $\begin{array}{r}7 \cdot 96 \\
23 \cdot 51 \\
2 \cdot 95\end{array}$ & $\begin{array}{r}7 \cdot 92 \\
23 \cdot 61 \\
2 \cdot 98\end{array}$ & $\begin{array}{r}7 \cdot 51 \\
21 \cdot 92 \\
2 \cdot 92\end{array}$ \\
\hline $\begin{array}{l}\text { Crude protein intake } \\
\text { Wt gain } \\
\text { TPE }\end{array}$ & SB-FM & & $\begin{array}{r}7 \cdot 57 \\
20 \cdot 42 \\
2 \cdot 69\end{array}$ & $\begin{array}{r}7 \cdot 97 \\
23 \cdot 80 \\
2 \cdot 98\end{array}$ & $\begin{array}{r}7 \cdot 78 \\
23 \cdot 93 \\
3 \cdot 08\end{array}$ & $\begin{array}{r}7 \cdot 92 \\
24 \cdot 65 \\
3 \cdot 16\end{array}$ & $\begin{array}{r}7.64 \\
23.99 \\
3.14\end{array}$ & $\begin{array}{r}7 \cdot 40 \\
23 \cdot 30 \\
3 \cdot 14\end{array}$ & $\begin{array}{r}7 \cdot 02 \\
21 \cdot 79 \\
3 \cdot 10\end{array}$ \\
\hline
\end{tabular}

SF, sunflower-seed meal; GN, groundnut meal; MM, meat meal; SB, soya-bean meal; FM, fish meal; $B$, barley; $M$, wheat middlings.

* For details, see p. 293 and Tables 2 and 3.

+ For details of composition, see Table $\mathbf{r}$.

Mixtures of comparatively poor-quality concentrates which individually give similar low values provide the opportunity of greatly enhanced performance. Mixtures of GN and MM in roughly equal proportions give much better results than either concentrate fed singly, with both series $\mathrm{I}$ and 2 protein concentrates. A similar effect is noticeable for SF-MM mixtures.

Synergists may be defined as two or more agents which, when combined, produce an effect greater than the additive effect of both when operating alone (Winburne, I962). Taking both series I and 2 protein concentrates, twenty sets of values in all, 


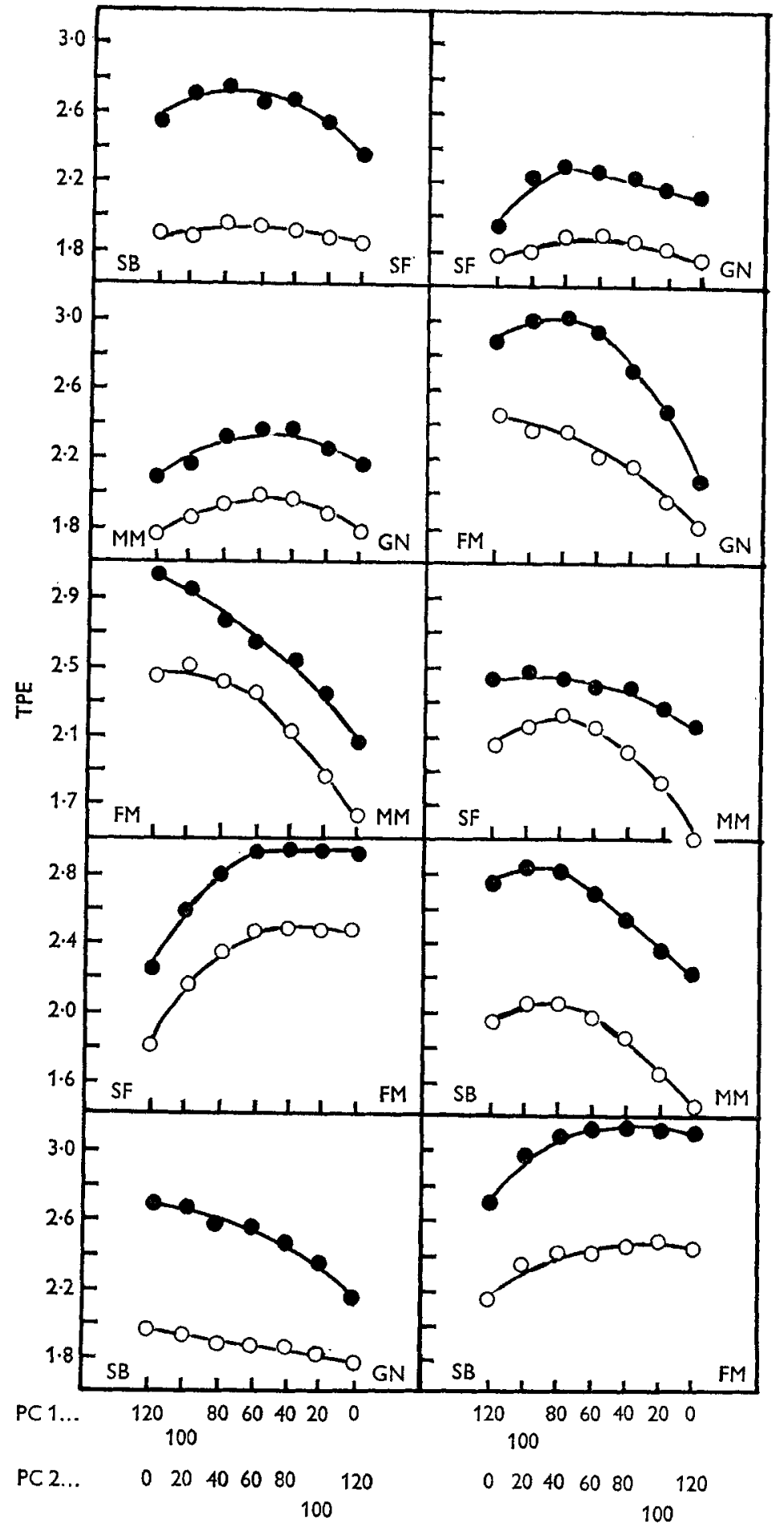

Relative amounts of PC1-PC 2 (w/w)

Fig. I. Total protein efficiency (g weight gain/g protein consumed; TPE) of diets with $180 \mathrm{~g}$ crude protein (nitrogen $\times 6.25) / \mathrm{kg}$, containing cereals $(60 \mathrm{~g}$ protein $/ \mathrm{kg}$ ) in addition to pairs of protein concentrates $\left(\mathrm{PC}_{\mathrm{I}}, \mathrm{PC}_{2}\right)$ mixed in varying proportions to contribute $\mathrm{I} 20 \mathrm{~g}$ protein $/ \mathrm{kg}$; (O), series I; (O) series 2. SB, soya-bean meal; SF, sunflower-seed meal; GN, groundnut meal; MM, meat meal; FM, fish meal; for details of protein concentrates and cereals, see $p$. 290. 
nineteen values exhibited some synergistic effect in that the performance of birds given the mixture was greater than that which would be predicted from the results obtained by feeding the components singly. The fact that mixtures displaying this synergistic effect predominated among combinations of the common and important protein supplements used in this work is very encouraging. Clearly a knowledge of the existence of, and an understanding of the reasons for such complementary effects would permit the optimum utilization of these materials, allowing advantage to be taken of particular market situations regarding availability and price.

Although the results were obtained with two different series of the same types of concentrate and the testing of each series was carried out with two very different types of chicken, the results are strikingly similar for the two series of protein concentrates. However, the possibility of variations of quality within a concentrate type which have already been amply demonstrated (e.g. Boyne, Carpenter \& Woodham, I96r; Carpenter \& Woodham, 1974) must lead to caution in assuming that the effects of mixing other samples of protein concentrates would necessarily be similar. The conclusion does, however, seem to be inevitable that whenever possible a mixture of protein concentrates should be used to supplement cereals rather than a single material. It would clearly be very useful if the ideal combinations in such mixtures could be predicted, and the most likely way of doing this would be by means of amino acid composition. Is it possible to explain the supplementary effects revealed by the biological results in terms of improved amino acid balance? If so it should be possible to predict the optimum combinations of any two protein concentrates by routine amino acid analysis.

\section{Chemical score $(C S)$ and essential amino acid index (EAAI)}

Block \& Mitchell (1946) proposed scoring protein foods on the basis of the essential amino acid which was in greatest deficit when compared to a reference protein, and whole-egg protein has been frequently chosen as the standard. The essential amino acid in greatest deficit is the limiting amino acid and CS, therefore, is given by the expression:

$$
\frac{\text { amount of limiting amino acid }(\%)}{\text { amount of the same amino acid in egg }(\%)} \times 100 \text {. }
$$

In most instances the limiting amino acid will be lysine, or methionine + cystine.

Oser (1951) suggested that it would be more reasonable to use an expression allowing for the provision of all the essential amino acids and not merely the most limiting amino acid. He proposed using the geometric mean of the values for the ratio, amount of essential amino acid:amount of that amino acid in egg, for all ten essential amino acids and this expression he termed EAAI.

It has been stated recently that because it is based on a single limiting amino acid, CS will tend to underestimate biological value and consequently EAAI is to be preferred, even allowing for the fact that such measurements are based on the analysis of protein hydrolysates and do not take into account differences in protein digestibility and amino acid availability (UN Protein Advisory Group, 1974). However, the EAAI concept has not been universally accepted and despite the UN Protein Advisory 
Table 6. The essential amino acid requirements of broiler chickens between 14 and $28 d$ of age*

\begin{tabular}{lcc}
\multicolumn{1}{c}{ Amino acid } & \multicolumn{2}{c}{ Requirement } \\
Threonine & $\mathrm{g} / \mathrm{kg}$ diet & $\mathrm{g} / \mathrm{kg}$ dietary protein \\
Glycine & $5 \cdot 0-5 \cdot 2$ & $28-29$ \\
Valine & $4 \cdot 8-5 \cdot 0$ & $27-28$ \\
Cystine + methionine & $6 \cdot 9-7 \cdot 1$ & $38-39$ \\
Isoleucine & $5 \cdot 8$ & 32 \\
Leucine & $<4 \cdot 8$ & $<27$ \\
Tyrosine + phenylalanine & $<10 \cdot 9-11 \cdot 2$ & $<58$ \\
Lysine & $8 \cdot 7$ & $61-62$ \\
Histidine & $<3 \cdot 4$ & 48 \\
Arginine & $<7 \cdot 6$ & $<19$ \\
Tryptophan & $<1 \cdot 4$ & $<42$ \\
& $*$ From Woodham \& Deans (1975).
\end{tabular}

Group (1974) pronouncement it is still widely felt that the extent to which a protein may be utilized is solely dependent upon the limiting amino acid (e.g. Bender, 1973).

The choice of reference protein is clearly critical. While egg protein may be satisfactory for materials which are to be evaluated for human consumption it seems sensible to suppose that a set of hypothetical 'target' values might be more appropriate in many instances. The FAO reference pattern (FAO, 1965) may be quoted as an example. In the present series of experiments using chickens the most appropriate reference would seem to be a hypothetical protein providing exactly the calculated requirements of the chick for each of the essential amino acids. These 'requirement' values (Table 6) were specially determined under the condition of the experiments described here and have been published fully elsewhere (Woodham \& Deans, 1975). They are in general agreement with values obtained by other workers using conventional diets, providing that the values are expressed as a percentage of the dietary protein content rather than as a percentage of the diet (Woodham \& Deans, 1975).

$\mathrm{CS}$ and EAAI were calculated for all the mixed diets tested in the present work. In calculating the latter all eleven of the amino acids known to be essential for the optimum growth of the chicken were taken into account, methionine and cystine being treated additively as one amino acid, as were tyrosine and phenylalanine. The amino acid composition of the cereals and protein concentrates used in preparing the mixtures are given in Table 7 and the contributions of lysine and of methionine+ cystine by mixtures of cereals with the individual protein concentrates are given in Table 8. The calculated values for CS and EAAI as well as the limiting amino acids in each of the mixtures tested are shown in Table 9 (series I protein concentrates) and Table Io (series 2 protein concentrates). The values for CS for both series of protein concentrates are shown in Fig. 2.

The EAAI for all mixtures tested were between 95 and 100 and the differences between mixtures were very small. This was due to the fact that in these near-practical formulations most of the essential amino acids were provided at levels greater than 
Table 7. Amounts of essential amino acids ( $\mathrm{g} / \mathrm{kg}$ diet) contributed by cereal combinations (barley $(B)$ and wheat middlings $(M)$ ) each providing $60 \mathrm{~g}$ protein $/ \mathrm{kg}$ diet, and five protein concentrates each providing $120 \mathrm{~g}$ protein $/ \mathrm{kg}$ diet

\begin{tabular}{|c|c|c|c|c|c|c|c|c|}
\hline & \multicolumn{3}{|c|}{ Cereals } & \multicolumn{5}{|c|}{ Protein concentrates } \\
\hline & $\begin{array}{c}\mathrm{Bg}_{96}+ \\
\mathrm{M}_{9} 88\end{array}$ & $\begin{array}{c}\mathrm{B}_{2}+ \\
\mathrm{M}_{3}\end{array}$ & B986 & $\begin{array}{l}\text { FM } \\
968\end{array}$ & $\begin{array}{c}\mathrm{MM} \\
977\end{array}$ & $\begin{array}{l}\text { GN } \\
97 \mathrm{I}\end{array}$ & $\begin{array}{l}\text { SB } \\
978\end{array}$ & $\begin{array}{l}\text { SF } \\
979\end{array}$ \\
\hline Threonine & $2 \cdot 3$ & $x \cdot 8$ & $2 \cdot 3$ & 5.0 & 3.7 & 3.6 & 47 & 4.6 \\
\hline Glycine & 3.0 & $2 \cdot 9$ & $2 \cdot 7$ & I I 4 & $16 \cdot 3$ & $7 \cdot 1$ & $4 \cdot 8$ & $6 \cdot 6$ \\
\hline Valine & $3 \cdot 0$ & $3 \cdot 0$ & $2 \cdot 7$ & $5 \cdot 8$ & $5 \cdot 5$ & $5 \cdot 3$ & $5 \cdot 6$ & $5 \cdot 5$ \\
\hline Cystine + methionine & $2 \cdot 7$ & $2 \cdot 6$ & $3 \cdot 0$ & $4 \cdot 4$ & $I \cdot 4$ & $2 \cdot 9$ & $3 \cdot 2$ & $5 \cdot 1$ \\
\hline Isoleucine & $2 \cdot 5$ & $2 \cdot 2$ & $2 \cdot 6$ & 4.7 & $3 \cdot 1$ & $4 \cdot 3$ & $5 \cdot 0$ & $4 \cdot 7$ \\
\hline Leucine & $4 \cdot 5$ & $4 \cdot I$ & 4.9 & $8 \cdot 0$ & $7 \cdot 0$ & 7.9 & $8 \cdot 9$ & $7 \cdot 4$ \\
\hline Tyrosine + phenylalanine & 5.0 & $5 \cdot 1$ & $5 \cdot 3$ & $7 \cdot 9$ & $6 \cdot 4$ & II'3 & $10 \cdot 6$ & $8 \cdot 2$ \\
\hline Lysine & $2 \cdot 8$ & $2 \cdot 7$ & $2 \cdot 6$ & $8 \cdot 9$ & $5 \cdot 9$ & 44 & $7 \cdot 3$ & $4 \cdot 2$ \\
\hline Histidine & $x \cdot 6$ & $x \cdot 4$ & $1 \cdot 5$ & $2 \cdot 3$ & $2 \cdot 2$ & 3.0 & $3 \cdot I$ & $2 \cdot 9$ \\
\hline Arginine & $4 \cdot 0$ & 3.5 & $3 \cdot 4$ & $8 \cdot 3$ & $8 \cdot 3$ & $14 \cdot 5$ & $9^{\circ} \circ$ & $10 \% 4$ \\
\hline \multirow[t]{4}{*}{ Tryptophan } & $I \cdot I$ & 0.7 & 0.9 & $1 \cdot 7$ & $I \cdot 4$ & $\mathrm{I} \cdot 3$ & $2 \cdot 3$ & $2 \cdot 2$ \\
\hline & \multicolumn{8}{|c|}{ Series 2} \\
\hline & \multicolumn{3}{|c|}{ Cereals } & \multicolumn{5}{|c|}{ Protein concentrates } \\
\hline & $\begin{array}{l}\text { B20 } \\
\text { M21 }\end{array}$ & $\begin{array}{c}\mathrm{B}_{3} 8 \\
\mathrm{M}_{47}\end{array}$ & & $\begin{array}{c}\text { FM } \\
\mathbf{3}^{\mathrm{I}}\end{array}$ & $\begin{array}{c}\mathrm{MM} \\
27\end{array}$ & $\begin{array}{c}\text { GN } \\
26\end{array}$ & $\begin{array}{l}\text { SB } \\
22\end{array}$ & $\begin{array}{l}\text { SF } \\
29\end{array}$ \\
\hline Threonine & $2 \cdot I$ & $I \cdot 8$ & & $5^{\circ} \circ$ & $3 \cdot 5$ & $3 \cdot I$ & 4.9 & $4 \cdot 3$ \\
\hline Glycine & $3 \cdot 0$ & $2 \cdot 4$ & & 10.3 & 15.6 & $6 \cdot 2$ & $5 \cdot 5$ & $6 \cdot 8$ \\
\hline Valine & $3 \cdot 0$ & $2 \cdot I$ & & $6 \cdot I$ & 5.0 & $4 \cdot 9$ & $6 \cdot 6$ & $6 \cdot 0$ \\
\hline Cystine + methionine & $2 \cdot 5$ & $2 \cdot 6$ & & $3 \%$ & $2 \cdot 3$ & $2 \cdot 4$ & $2 \cdot 8$ & $5 \cdot 2$ \\
\hline Isoleucine & $2 \cdot 2$ & $1 \cdot 5$ & & $5 \cdot 0$ & 3.0 & $4 \cdot 1$ & $6 \cdot 2$ & $5 \cdot 2$ \\
\hline Leucine & $4 \cdot 2$ & $3 \cdot 5$ & & $8 \cdot 5$ & 7.0 & $7 \cdot 3$ & $9 \cdot 8$ & $7 \cdot 4$ \\
\hline Tyrosine + phenylalanine & 4.8 & $4^{-1}$ & & $8 \cdot 9$ & 6.6 & 10.7 & 10.9 & 9.0 \\
\hline Lysine & $2 \cdot 6$ & $2 \cdot 1$ & & 8.8 & $6 \cdot 2$ & 3.8 & $8 \cdot 2$ & $4 \cdot 4$ \\
\hline Histidine & $\mathrm{I} \cdot 4$ & $I \cdot I$ & & $2 \cdot 8$ & $2 \cdot 4$ & $2 \cdot 6$ & $3 \cdot 2$ & $3 \cdot 1$ \\
\hline Arginine & 35 & $3 \cdot 1$ & & $8 \cdot 3$ & $8 \cdot 5$ & $12 \cdot 0$ & $9 \cdot 0$ & $10 \cdot 2$ \\
\hline Tryptophan & $0 \cdot 6$ & 0.5 & & $I \cdot I$ & 0.7 & $\mathrm{I} \cdot \mathrm{O}$ & $2 \cdot 3$ & $\mathrm{I} \cdot 4$ \\
\hline
\end{tabular}

FM, fish meal; MM, meat meal; GN, groundnut meal; SB, soya-bean meal; SF, sunflower-seed meal.

Table 8. Amounts ( $\mathrm{g} / \mathrm{kg}$ diet) of lysine and cystine + methionine contributed by basal cereal combinations (barley $(B)$ and wheat middlings $(M)$ ) with the individual series $\mathrm{I}$ and 2 protein concentrates*

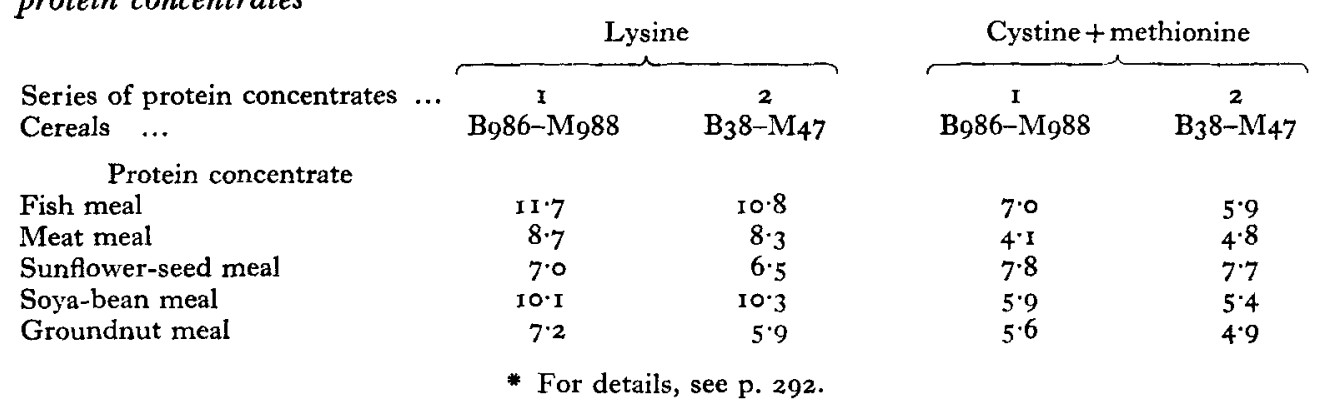


Table 9. Series I protein concentrates*. Limiting amino acid (LAA), essential amino acid index $(E A A I) \dagger$ and chemical score $(C S) \dagger$ for cereal-based diets supplemented with pairs of protein concentrates $\left(P C \mathrm{r}, P C_{2}\right)$ mixed in varying proportions to contribute $120 \mathrm{~g}$ protein/kg diet

\begin{tabular}{|c|c|c|c|c|c|c|c|c|c|}
\hline & $\mathrm{PC}_{1}-\mathrm{PC}_{2}$ & Basal cereals* & $120: 0$ & $100: 20$ & $80: 40$ & $60: 60$ & $40: 80$ & $20: 100$ & $0: 120$ \\
\hline $\begin{array}{l}\text { LAA } \\
\text { EAAI } \\
\text { CS }\end{array}$ & MM-GN & & $\begin{array}{c}C+M \\
96.9 \\
70.6\end{array}$ & $\begin{array}{r}C+M \\
97 \cdot 2 \\
75.0\end{array}$ & $\begin{array}{c}\mathrm{C}+\mathrm{M} \\
97.4 \\
79.3\end{array}$ & $\begin{array}{c}\mathrm{C}+\mathrm{M} \\
97 \cdot 6 \\
83 \cdot 6\end{array}$ & $\begin{array}{c}C+M \\
97.7 \\
87.9\end{array}$ & $\begin{array}{r}\text { LYS } \\
97.9 \\
85^{\circ} 6\end{array}$ & $\begin{array}{r}\text { LYS } \\
98 \cdot 0 \\
82 \cdot 7\end{array}$ \\
\hline $\begin{array}{l}\text { LAA } \\
\text { EAAI } \\
\text { CS }\end{array}$ & FM-GN & & $\begin{array}{l}- \\
100 \\
100\end{array}$ & $\begin{array}{l}- \\
100 \\
100\end{array}$ & $\begin{array}{l}- \\
100 \\
100\end{array}$ & $\begin{array}{l}- \\
100 \\
100\end{array}$ & $\begin{array}{l}- \\
100 \\
100\end{array}$ & $\begin{array}{c}\text { LYS } \\
99 \cdot 2 \\
91 \cdot 3\end{array}$ & $\begin{array}{r}\text { LYS } \\
98 \cdot 0 \\
82 \cdot 7\end{array}$ \\
\hline $\begin{array}{l}\text { LAA } \\
\text { EAAI } \\
\text { CS }\end{array}$ & FM-MM & B986-M988 & $\begin{array}{l}- \\
100 \\
100\end{array}$ & $\begin{array}{l}- \\
100 \\
100\end{array}$ & $\begin{array}{l}- \\
100 \\
100\end{array}$ & $\begin{array}{c}\mathrm{C}+\mathrm{M} \\
99 \cdot 7 \\
96.5\end{array}$ & $\begin{array}{c}\mathrm{C}+\mathrm{M} \\
98.8 \\
87.9\end{array}$ & $\begin{array}{r}\mathrm{C}+\mathrm{M} \\
97.9 \\
79.3\end{array}$ & $\begin{array}{r}\mathrm{C}+\mathrm{M} \\
96.9 \\
70.6\end{array}$ \\
\hline $\begin{array}{l}\text { LAA } \\
\text { EAAI } \\
\text { CS }\end{array}$ & SF-MM & & $\begin{array}{c}\text { LYS } \\
98 \cdot 0 \\
80.4\end{array}$ & $\begin{array}{c}\text { LYS } \\
98 \cdot 4 \\
83^{\circ} 7\end{array}$ & $\begin{array}{c}\text { LYS } \\
98 \cdot 7 \\
86.9\end{array}$ & $\begin{array}{c}\text { LYS } \\
99^{\cdot 1} \\
90^{\prime} 2\end{array}$ & $\begin{array}{c}C+M \\
98.6 \\
9 I \cdot 9\end{array}$ & $\begin{array}{r}\mathrm{C}+\mathrm{M} \\
97 \cdot 8 \\
8 \mathrm{r} \cdot 3\end{array}$ & $\begin{array}{r}C+M \\
96.9 \\
70.6\end{array}$ \\
\hline $\begin{array}{l}\text { LAA } \\
\text { EAAI } \\
\text { CS }\end{array}$ & SB-MM & & $\begin{array}{l}- \\
100 \\
100\end{array}$ & $\begin{array}{r}\mathrm{C}+\mathrm{M} \\
99^{\circ} 7 \\
96^{\circ} 5\end{array}$ & $\begin{array}{c}C+M \\
99 \cdot 2 \\
9 \mathrm{I} \cdot 3\end{array}$ & $\begin{array}{c}C+M \\
98 \cdot 7 \\
86 \cdot 2\end{array}$ & $\begin{array}{c}C+M \\
98 \cdot I \\
81 \cdot 0\end{array}$ & $\begin{array}{r}\mathrm{C}+\mathrm{M} \\
97.5 \\
75.8\end{array}$ & $\begin{array}{r}C+M \\
96.9 \\
70.6\end{array}$ \\
\hline $\begin{array}{l}\text { LAA } \\
\text { EAAI } \\
\text { CS }\end{array}$ & SB-GN & & $\begin{array}{l}- \\
100 \\
100\end{array}$ & $\begin{array}{r}\mathrm{C}+\mathrm{M} \\
99^{\circ} 9 \\
99^{\circ} \mathrm{I}\end{array}$ & $\begin{array}{c}C+M \\
99 \cdot 8 \\
98 \cdot 2\end{array}$ & $\begin{array}{c}C+M \\
99 \cdot 6 \\
97.4\end{array}$ & $\begin{array}{r}\text { LYS } \\
99^{\circ} 0 \\
92 \cdot 7\end{array}$ & $\begin{array}{c}\text { LYS } \\
98 \cdot 4 \\
87 \cdot 1\end{array}$ & $\begin{array}{r}\text { LYS } \\
97 \cdot 7 \\
81 \cdot 6\end{array}$ \\
\hline $\begin{array}{l}\text { LAA } \\
\text { EAAI } \\
\text { CS }\end{array}$ & SB-SF & & $\begin{array}{l}- \\
100 \\
100\end{array}$ & $\begin{array}{l}- \\
100 \\
100\end{array}$ & $\begin{array}{l}- \\
100 \\
100\end{array}$ & $\begin{array}{c}\text { LYS } \\
99^{\prime} 7 \\
97^{\circ} 1\end{array}$ & $\begin{array}{c}\text { LYS } \\
99^{-2} \\
9 I^{-1}\end{array}$ & $\begin{array}{c}\text { LYS } \\
98 \cdot 6 \\
85 \cdot 2\end{array}$ & $\begin{array}{r}\text { LYS } \\
97 \cdot 9 \\
79 \cdot 3\end{array}$ \\
\hline $\begin{array}{l}\text { LAA } \\
\text { EAAI } \\
\text { CS }\end{array}$ & SF-FM & $\mathrm{B}_{2}-\mathrm{M}_{3}$ & $\begin{array}{r}\text { LYS } \\
97 \cdot 9 \\
79 \cdot 3\end{array}$ & $\begin{array}{r}\text { LYS } \\
98 \cdot 9 \\
88 \cdot 3\end{array}$ & $\begin{array}{c}\text { LYS } \\
99 \cdot 8 \\
97.3\end{array}$ & $\begin{array}{l}- \\
100 \\
100\end{array}$ & $\begin{array}{l}- \\
100 \\
100\end{array}$ & $\begin{array}{l}- \\
100 \\
100\end{array}$ & $\begin{array}{l}- \\
100 \\
100\end{array}$ \\
\hline $\begin{array}{l}\text { LAA } \\
\text { EAAI } \\
\text { CS }\end{array}$ & SF-GN & & $\begin{array}{c}\text { LYS } \\
97 \cdot 9 \\
79 \cdot 3\end{array}$ & $\begin{array}{r}\text { LYS } \\
98 \cdot 0 \\
79 \cdot 6\end{array}$ & $\begin{array}{l}\text { LYS } \\
98 \cdot 0 \\
80 \cdot 0\end{array}$ & $\begin{array}{l}\text { LYS } \\
98 \cdot 0 \\
80^{\circ} \cdot 4\end{array}$ & $\begin{array}{l}\text { LYS } \\
98 \cdot \mathbf{x} \\
80 \cdot 8\end{array}$ & $\begin{array}{r}\text { LYS } \\
98 \cdot 1 \\
81 \cdot 2\end{array}$ & $\begin{array}{l}\text { LYS } \\
97 \cdot 7 \\
81.6\end{array}$ \\
\hline $\begin{array}{l}\text { LAA } \\
\text { EAAI } \\
\text { CS }\end{array}$ & SB-FM & B986 & $\begin{array}{l}- \\
100 \\
100\end{array}$ & $\begin{array}{l}- \\
100 \\
100\end{array}$ & $\begin{array}{l}-\overline{100} \\
100\end{array}$ & $\begin{array}{l}\overline{100} \\
100\end{array}$ & $\begin{array}{l}- \\
100 \\
100\end{array}$ & $\begin{array}{l}- \\
100 . . \\
100\end{array}$ & $\begin{array}{l}- \\
100 \\
100\end{array}$ \\
\hline
\end{tabular}

$\mathrm{C}+\mathrm{M}$, cystine + methionine; LYS, lysine; MM, meat meal; GN, groundnut meal; FM, fish meal; $\mathrm{SF}$, sunflower-seed meal; SB, soya-bean meal; B, barley; $M$, wheat middlings.

* For details, see p. 290 and Tables 2 and 3.

$\dagger$ (Amount of limiting amino acid/the chick's requirements for the same amino acid) $\times 100$.

$\ddagger$ Geometric mean for the ratio, amount of essential amino acid:the chick's requirements for that amino acid, for all ten essential amino acids.

requirement (see Table II) and it was clear that in such diets the EAAI could give no useful indication of differences in quality. This was borne out by the observation that large changes in TPE were not reflected in the EAAI. CS, on the other hand, did vary considerably as the proportions of protein concentrates in the mixtures were changed (Fig. 2). Differences in the amino acid composition of corresponding pairs of protein concentrates used in series $I$ and 2, notably the GN, MM and SB, were reflected in the CS but in general it was clear from Fig. 2 that changes in amino acid composition brought about by mixing protein concentrates were fairly similar for the two series studied. 
Table 10. Series 2 protein concentrates*. Limiting amino acid (LAA), essential amino acid index $(E A A I) \dagger$ chemical score $(C S) \downarrow$ for cereal-based diets $\$$ supplemented with pairs of protein concentrates $\left(P C_{\mathrm{I}}, P C_{2}\right)$ mixed in varying proportions to contribute $120 \mathrm{~g}$ protein!kg diet

Relative amounts of $\mathrm{PC} 1-\mathrm{PC}_{2}(\mathrm{w} / \mathrm{w})$

\begin{tabular}{|c|c|c|c|c|c|c|c|c|c|}
\hline & & & & & & & & & \\
\hline & $\mathrm{PC}_{1}-\mathrm{PC}_{2}$ & Basal cereals* & $120: 0$ & $100: 20$ & $80: 40$ & $60: 60$ & $40: 80$ & $20: 100$ & $0: 120$ \\
\hline $\begin{array}{l}\text { LAA } \\
\text { EAAI } \\
\text { CS }\end{array}$ & SF-GN & & $\begin{array}{r}\text { LYS } \\
98 \cdot 1 \\
80.9\end{array}$ & $\begin{array}{c}\text { LYS } \\
98 \cdot 0 \\
79 \cdot 7\end{array}$ & $\begin{array}{c}\text { LYS } \\
97.8 \\
78.6\end{array}$ & $\begin{array}{r}\text { LYS } \\
97 \cdot 7 \\
77^{\circ} 4\end{array}$ & $\begin{array}{r}\text { LYS } \\
97 \cdot 6 \\
76 \cdot 3\end{array}$ & $\begin{array}{c}\text { LYS } \\
96 \cdot 7 \\
75 \cdot 1\end{array}$ & $\begin{array}{r}\text { LYS } \\
95^{\circ} 8 \\
74^{\circ} 0\end{array}$ \\
\hline $\begin{array}{l}\text { LAA } \\
\text { EAAI } \\
\text { CS }\end{array}$ & $M M-G N$ & & $\begin{array}{c}\mathrm{C}+\mathrm{M} \\
97 \cdot 7 \\
82 \cdot 4\end{array}$ & $\begin{array}{r}C+M \\
97 \cdot 8 \\
82 \cdot 7\end{array}$ & $\begin{array}{c}C+M \\
97 \cdot 6 \\
83 \cdot I\end{array}$ & $\begin{array}{c}\mathrm{C}+\mathrm{M} \\
97^{\circ} \mathbf{2} \\
83^{\circ} \cdot\end{array}$ & $\begin{array}{r}\text { LYS } \\
96 \cdot 8 \\
83^{\prime} \cdot 2\end{array}$ & $\begin{array}{c}\text { LYS } \\
96 \cdot 3 \\
78 \cdot 6\end{array}$ & $\begin{array}{r}\text { LYS } \\
95^{\circ} 8 \\
74^{\circ} 0\end{array}$ \\
\hline $\begin{array}{l}\text { LAA } \\
\text { EAAI } \\
\text { CS }\end{array}$ & SF-MM & & $\begin{array}{c}\text { LYS } \\
98 \cdot I \\
80.9\end{array}$ & $\begin{array}{c}\text { LYS } \\
98 \cdot 5 \\
84 \cdot 3\end{array}$ & $\begin{array}{r}\text { LYS } \\
98.8 \\
87.8\end{array}$ & $\begin{array}{r}\text { LYS } \\
99 \cdot 2 \\
91 \cdot 2\end{array}$ & $\begin{array}{r}\text { LYS } \\
99 \cdot 4 \\
94 \cdot 7\end{array}$ & $\begin{array}{r}\mathrm{C}+\mathrm{M} \\
98 \cdot 9 \\
90 \cdot 6\end{array}$ & $\begin{array}{r}\mathrm{C}+\mathrm{M} \\
97 \cdot 7 \\
82.4\end{array}$ \\
\hline $\begin{array}{l}\text { LAA } \\
\text { EAAI } \\
\text { CS }\end{array}$ & SB-MM & $\mathrm{B}_{20}-\mathrm{M}_{2 \mathrm{I}}$ & $\begin{array}{c}\mathrm{C}+\mathrm{M} \\
99 \cdot 3 \\
92 \cdot 7\end{array}$ & $\begin{array}{r}\mathrm{C}+\mathbf{M} \\
99^{\circ} \mathbf{I} \\
9 \mathrm{I}^{\circ} \cdot 0\end{array}$ & $\begin{array}{c}\mathrm{C}+\mathrm{M} \\
99 \cdot 0 \\
89 \cdot 3\end{array}$ & $\begin{array}{c}\mathrm{C}+\mathrm{M} \\
98.8 \\
87.5\end{array}$ & $\begin{array}{c}C+M \\
98.6 \\
85.8\end{array}$ & $\begin{array}{r}\mathrm{C}+\mathrm{M} \\
98 \cdot 4 \\
84 . \mathrm{I}\end{array}$ & $\begin{array}{r}\mathrm{C}+\mathrm{M} \\
97.7 \\
82.4\end{array}$ \\
\hline $\begin{array}{l}\text { LAA } \\
\text { EAAI } \\
\text { CS }\end{array}$ & SB-GN & & $\begin{array}{c}\mathrm{C}+\mathrm{M} \\
99 \cdot 3 \\
92.7\end{array}$ & $\begin{array}{r}\mathrm{C}+\mathrm{M} \\
99 \cdot 2 \\
91 \cdot 3\end{array}$ & $\begin{array}{c}\mathrm{C}+\mathrm{M} \\
99^{\circ} 0 \\
90^{\circ} 0\end{array}$ & $\begin{array}{c}C+M \\
98.9 \\
88.6\end{array}$ & $\begin{array}{c}\mathrm{C}+\mathrm{M} \\
97 \cdot 9 \\
87.2\end{array}$ & $\begin{array}{c}\text { LYS } \\
96 \cdot 9 \\
82 \cdot 5\end{array}$ & $\begin{array}{r}\text { LYS } \\
95^{\circ} 8 \\
74^{\circ}\end{array}$ \\
\hline $\begin{array}{l}\text { LAA } \\
\text { EAAI } \\
\text { CS }\end{array}$ & SB-SF & & $\begin{array}{c}\mathrm{C}+\mathrm{M} \\
99 \cdot 3 \\
92 \cdot 7\end{array}$ & $\begin{array}{r}\mathrm{C}+\mathrm{M} \\
99^{\circ} 9 \\
99^{\circ} 3\end{array}$ & $\begin{array}{r}- \\
100 \\
100\end{array}$ & $\begin{array}{l}- \\
100 \\
100\end{array}$ & $\begin{array}{r}\text { LYS } \\
99^{\circ 6} \\
95.6\end{array}$ & $\begin{array}{c}\text { LYS } \\
98 \cdot 9 \\
88 \cdot 2\end{array}$ & $\begin{array}{r}\text { LYS } \\
98 \cdot I \\
80 \cdot 9\end{array}$ \\
\hline $\begin{array}{l}\text { LAA } \\
\text { EAAI } \\
\text { CS }\end{array}$ & FM-GN & & $\begin{array}{l}- \\
100 \\
100\end{array}$ & $\begin{array}{l}- \\
100 \\
100\end{array}$ & $\begin{array}{c}\mathrm{C}+\mathrm{M} \\
99 \cdot 7 \\
97.2\end{array}$ & $\begin{array}{c}\mathrm{C}+\mathrm{M} \\
99^{\circ} 2 \\
94^{\circ} 4\end{array}$ & $\begin{array}{c}\text { LYS } \\
98 \cdot 0 \\
87 \cdot 1\end{array}$ & $\begin{array}{c}\text { LYS } \\
96 \cdot 7 \\
77 \cdot 7\end{array}$ & $\begin{array}{r}\text { LYS } \\
94 \cdot 7 \\
68 \cdot 2\end{array}$ \\
\hline $\begin{array}{l}\text { LAA } \\
\text { EAAI } \\
\text { CS }\end{array}$ & FM-MM & & $\begin{array}{l}- \\
100 \\
100\end{array}$ & $\begin{array}{c}C+M \\
100 \\
99.6\end{array}$ & $\begin{array}{c}\mathrm{C}+\mathrm{M} \\
99 \cdot 7 \\
96.5\end{array}$ & $\begin{array}{c}\mathrm{C}+\mathrm{M} \\
99.4 \\
93.4\end{array}$ & $\begin{array}{c}\mathrm{C}+\mathrm{M} \\
99 \cdot \mathrm{I} \\
90 \cdot 3\end{array}$ & $\begin{array}{r}\mathrm{C}+\mathrm{M} \\
98.5 \\
87.2\end{array}$ & $\begin{array}{r}\mathrm{C}+\mathrm{M} \\
96 \cdot 5 \\
84 \cdot \mathrm{I}\end{array}$ \\
\hline $\begin{array}{l}\text { LAA } \\
\text { EAAI } \\
\text { CS }\end{array}$ & $\mathrm{SF}-\mathrm{FM}$ & $M_{47}$ & $\begin{array}{r}\text { LYS } \\
97 \cdot 4 \\
75 \cdot 1\end{array}$ & $\begin{array}{c}\text { LYS } \\
98 \cdot 4 \\
83 \cdot 4\end{array}$ & $\begin{array}{r}\text { LYS } \\
99^{\cdot 2} \\
91.7\end{array}$ & $\begin{array}{c}\text { LYS } \\
100 \\
99^{\circ} 9\end{array}$ & $\begin{array}{l}- \\
100 \\
100\end{array}$ & $\begin{array}{l}- \\
100 \\
100\end{array}$ & $\begin{array}{l}- \\
100 \\
100\end{array}$ \\
\hline $\begin{array}{l}\text { LAA } \\
\text { EAAI } \\
\text { CS }\end{array}$ & SB-FM & & $\begin{array}{c}C+M \\
99.5 \\
94.4\end{array}$ & $\begin{array}{r}\mathrm{C}+\mathrm{M} \\
99.6 \\
95.8\end{array}$ & $\begin{array}{c}\mathrm{C}+\mathrm{M} \\
99 \cdot 7 \\
97 \cdot 2\end{array}$ & $\begin{array}{c}\mathrm{C}+\mathrm{M} \\
99.9 \\
98.6\end{array}$ & $\begin{array}{l}- \\
100 \\
100\end{array}$ & $\begin{array}{l}- \\
100 \\
100\end{array}$ & $\begin{array}{l}- \\
100 \\
100\end{array}$ \\
\hline
\end{tabular}

LYS, lysine; $C+M$, cystine + methionine; SF, sunflower-seed meal; GN, groundnut meal; $M M$, meat meal; SB, soya-bean meal; FM, fish meal; B, barley; $M$, wheat middlings.

* For details, see p, 290 and Tables 2 and 3.

$\dagger$ (Amount of limiting amino acid/the chick's requirements for the same amino acid) $\times$ roo.

$\ddagger$ Geometric mean for the ratio, amount of essential amino acid: the chick's requirements for that amino acid, for all ten essential amino acids.

$\S$ For details of composition, see Table $\mathrm{I}$.

Comparison of Figs $\mathrm{I}$ and 2 showed that in some mixtures changes in nutritive value as shown by the TPE measurements may be approximately predicted from the amino acid composition. Reasonable agreement between CS and TPE values were shown in the instances of MM-GN, FM-MM, SF-FM and SB-GN. However, in no instance was the agreement absolute, and in particular it was not possible to predict the increased TPE values obtained by mixing a small quantity of MM with SB or GN with FM. The clear and reproducible improvement obtained by such 


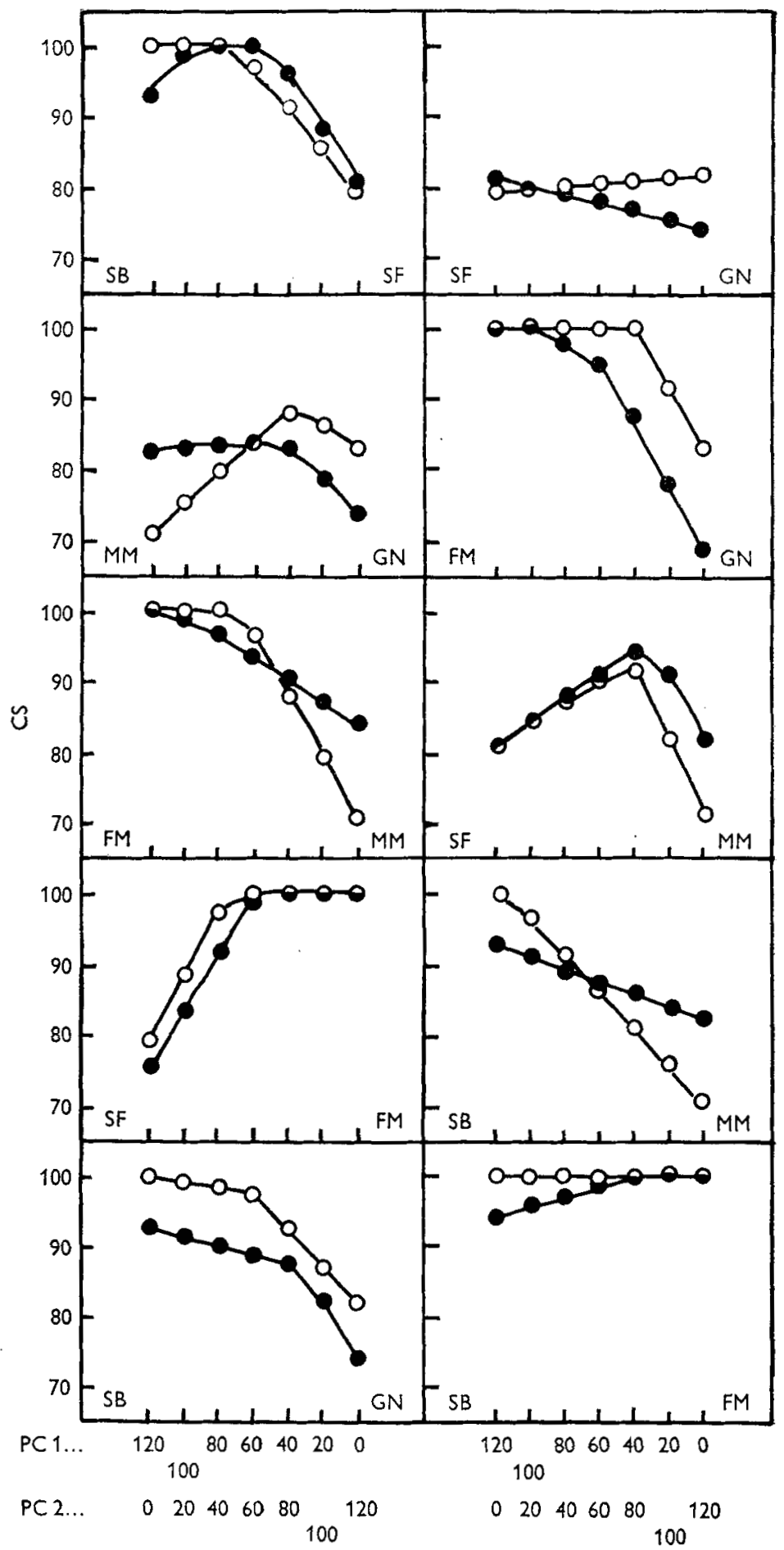

Relative amounts of PC 1-PC 2 (w/w)

Fig. 2. Chemical scores ([amount of limiting amino acid/the chick's requirements for the sameamino acid] $\times 100$; CS) for diets with $180 \mathrm{~g}$ crude protein (nitrogen $\times 6.25) / \mathrm{kg}$, containing cereals $(6 \circ \mathrm{g}$ protein $/ \mathrm{kg})$ in addition to pairs of protein concentrates $(\mathrm{PCr}, \mathrm{PC2})$ mixed in varying proportions to contribute $\mathrm{I} 20 \mathrm{~g}$ protein $/ \mathrm{kg}$; $(O)$, series $\mathrm{I} ;(\bullet)$, series 2 . SB, soya-bean meal; SF, sunflower-seed meal; GN, groundnut meal; MM, meat meal; FM, fish meal; for details . of protein concentrates and cereals, see p. 290. 
304 A. A. Woodham and P. S. Deans

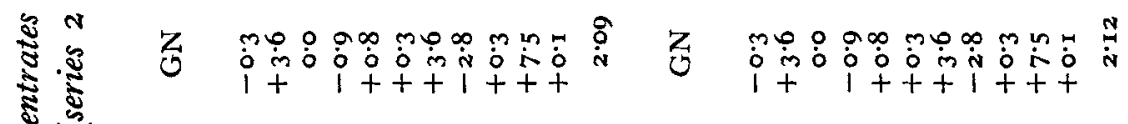

竞.

胥

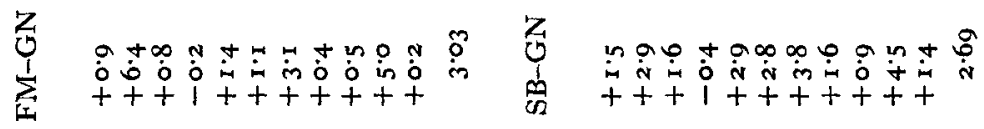

के हे

苋年

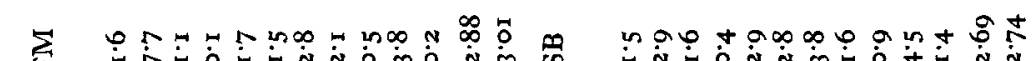

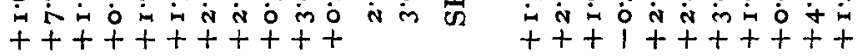

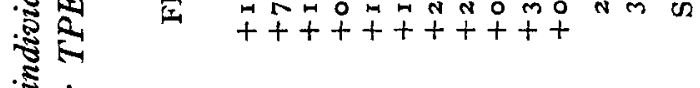

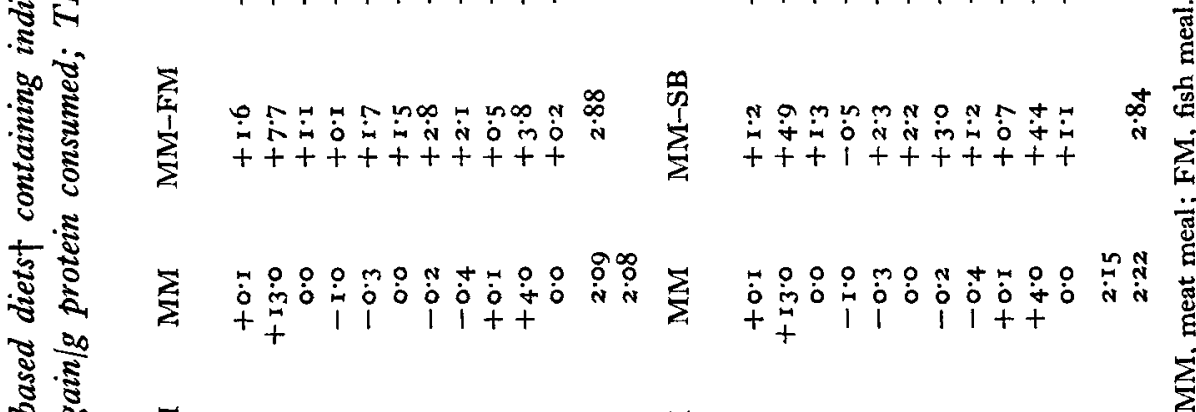

$\frac{2}{2} \frac{8}{8}$

$\sum_{\substack{\sum_{0} \\ 0}}^{\longrightarrow}$

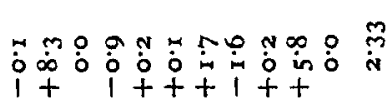

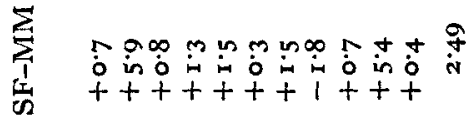

bे

$\frac{\pi_{0}^{\circ}}{30}$

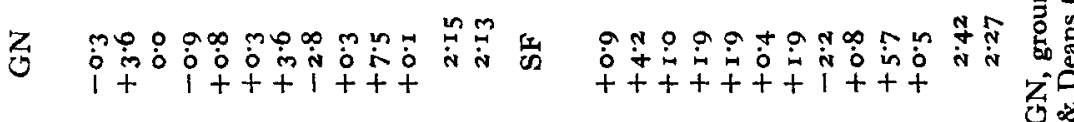

हี้

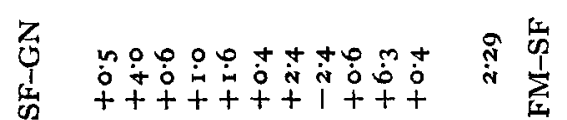

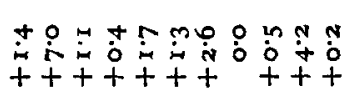

焉

胥

ह

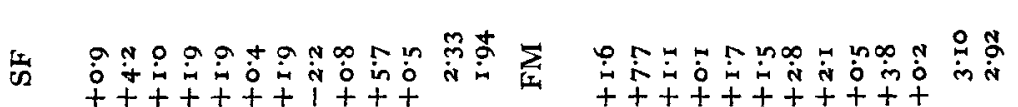

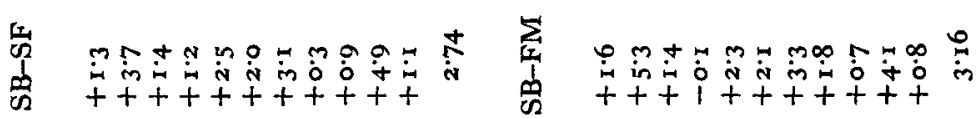

Q

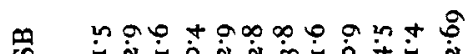

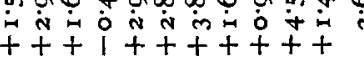




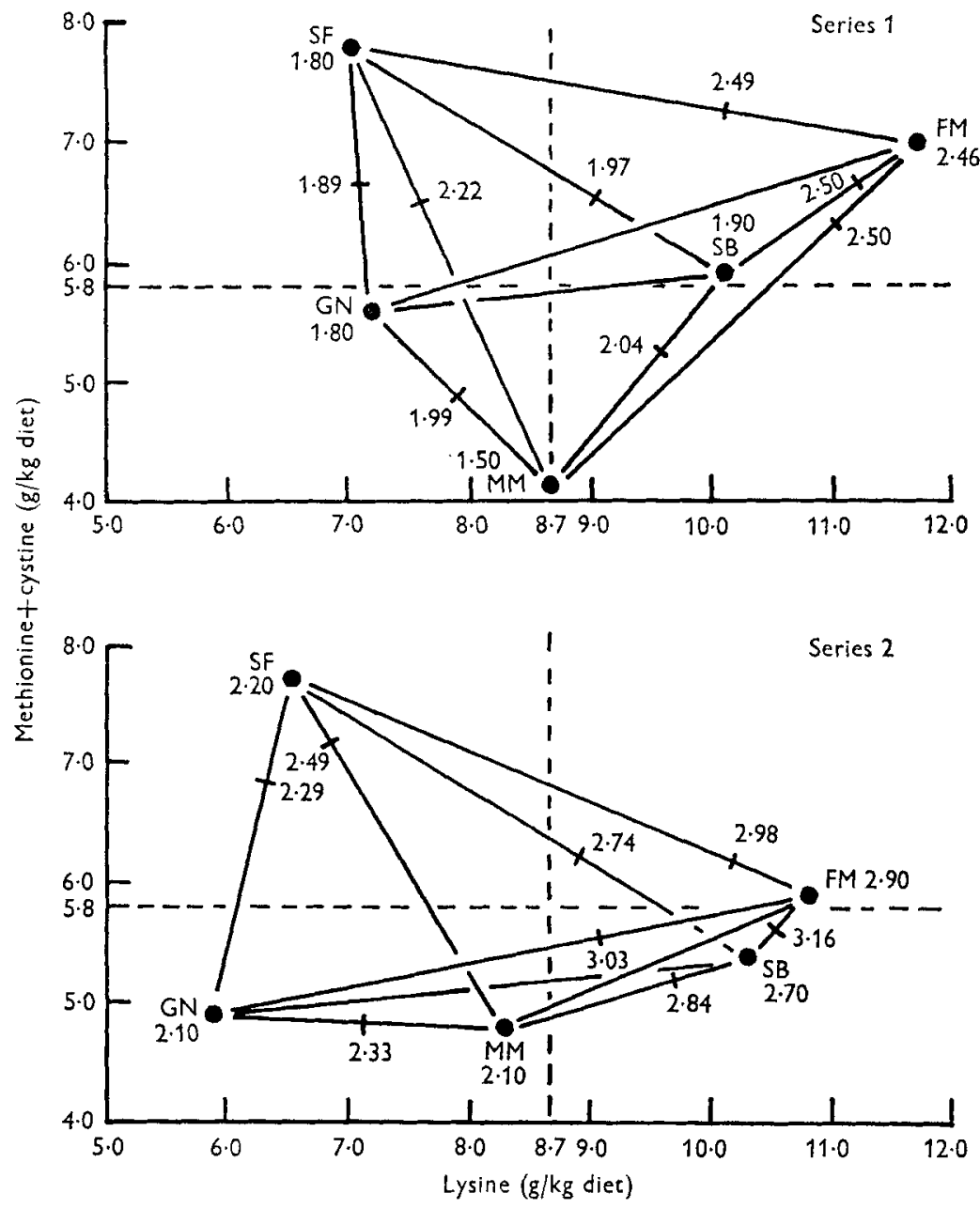

Fig. 3. The content of lysine and of sulphur amino acids in mixtures of protein concentrates with cereals, and the total protein efficiency ( $\mathrm{g}$ weight gain/g protein consumed; TPE) of the individual protein concentrates and of the best mixtures. (-- ), Requirement of each amino acid; SF, sunflower-seed meal; FM, fish meal; SB, soya-bean meal; GN, groundnut meal; MM, meat meal. For details of protein concentrates and cereals, see p. 290.

additions was not due to a complementary effect involving the provision, by one component of the mixture, of amino acids which were lacking in the other component. Consideration of the situation with regard to mixtures of SF and GN illustrates the difficulties. The GN in series I protein concentrates was superior to that in series 2 in that it had a markedly higher lysine content. Replacement of SF by GN in the series I protein concentrates caused a progressive increase in the CS value whereas in the series 2 protein concentrates the replacement caused a progressive reduction in the $\mathrm{CS}$ value. However, for both series $\mathrm{I}$ and 2 protein concentrates all the mixtures were limiting in lysine. Despite this in both series $\mathrm{x}$ and 2 protein concentrates the 
intermediate mixtures were superior in nutritive value to the diets containing only $\mathrm{GN}$ or SF.

The publications referred to previously (Block \& Mitchell, 1946; Bressani \& Elias, I 968) all attribute effects such as those demonstrated here to over-all improvements in the amino acid composition achieved by each component contributing something lacking in the other. This is not the explanation in the present series of experiments. In the mixtures studied the only amino acid which was limiting was lysine or the sulphur amino acids and differences in nutritive value were even found in some instances between mixtures in which the provision of all essential amino acids was adequate. For example, all series I SB-FM mixtures had CS values of 100 but there were marked differences in TPE between them. Similar situations have been noted previously. For example, most of the 'TPE' diets containing FM described by Carpenter \& Woodham (1974) provided more than the calculated requirements of the chick for amino acids, but differences in TPE were nevertheless found.

An attempt has been made to show diagrammatically the relationship between TPE and dietary lysine and cystine + methionine levels for both series of protein concentrates (Fig. 3). From this Fig. the actual levels of these amino acids in each mixture used can be obtained by dividing the line joining the constituents of the pair of concentrates concerned into six equal portions. The TPE of the best mixture of each set has been inserted on the line. All mixtures in the upper right quadrant of Fig. 3 contain adequate lysine and cystine + methionine. Those in the lower left quadrant of Fig. 3 are deficient in both, while those in the upper left and lower right quadrants of Fig. 3 are lacking in lysine and in cystine + methionine respectively. It is clear at once that while high TPE values tend to occur chiefly in the upper right quadrant of Fig. 3 as might be expected, they do not do so exclusively. Similarly, comparatively low TPE values tend to occur in the lower left quadrant of Fig. 3 but are found elsewhere also. Selection of combinations with the highest CS could be very misleading. In both series of protein concentrates for example, a diet containing $\mathrm{SB}$ as the only supplement to cereals would on the basis of amino acid composition appear to be superior to any combination of SB with MM, yet in fact the replacement of one-third of the SB by MM gave superior performance in growing chicks. Clearly CS must be considered an imperfect indicator of quality, albeit perhaps the best one based on amino acid composition which is available at present. Attempts to produce a more satisfactory measure by making allowance for excesses as well as deficiencies in the provision of various amino acids, essential and non-essential, have failed, possibly because excesses of some amino acids may be more deleterious than quantitatively similar excesses of others. It might be objected that differences in the digestibility or availability of the amino acids in the pairs of protein concentrates might account for some of the discrepancies noted but as CS is always calculated from total amino acid composition it was decided that in the present work the usefulness of CS and EAAI should be assessed under the conditions in which they would normally be used. The effect of taking availability into account was however tested by allocating extreme values to the samples and re-calculating CS on this basis. As an example the FM lysine was assumed to be $90 \%$ available and that of GN $75 \%$ available 
(Carpenter \& Woodham, 1974). The resulting curve obtained for the CS of FM-GN was of course displaced downwards, but the configuration was unaltered.

The amounts by which individual essential amino acids exceed or fall short of the requirements listed in Table 6 are shown in Table i 1 for each of the diets containing single protein concentrates (series 2 only) and also for the best mixture, i.e. the mixture which gives the highest TPE for each pair. Examination of this table reveals that in some instances, e.g. SB-SF, the improved performance in the best mixture may be attributable to the fact that each component is making good a deficiency in the other. On the other hand it would seem that such an explanation cannot be invoked for the improvement of FM and SB on partial replacement with GN and MM respectively, and in such instances it will be noticed that there is a reduction in the excesses of some of the essential amino acids. If the improvement in chick growth is to be attributed to an improvement in amino acid composition this must mean that the reduction in the levels of a number of amino acids has resulted in a better over-all amino acid balance. If this hypothesis is correct then any measure such as CS which is solely dependent upon the level of the first limiting amino acid must be inadequate. A high TPE value appears to be associated in our experiments not only with the avoidance of amino acid deficits but also with minimizing surpluses. For example, the replacement of FM by SB to give the highest TPE value of any diet of our series of protein concentrates cannot be explained by the removal of any deficiencies in the FM-containing diet but it will be noted that the glycine level of the latter has been markedly reduced.

We are indebted to Mr W. R. Hepburn who carried out the amino acid analysis of hydrolysates of the cereals and protein concentrates used in this study and to Miss Margaret Findlay for her conscientious care of the chickens used in the growth experiments. The tryptophan estimations for the series 2 samples were carried out by Dr N. A. Matheson.

\section{REFERENCES}

Bender, A. E. (1 973). In Proteins in Human Nutrition, Ch. I I, p. I67 [J. W. G. Porter and B. A. Rolls, editors]. London and New York: Academic Press.

Block, R. J. \& Mitchell, H. H. (1946). Nutr. Abstr. Rev. 16, 273.

Boyne, A. W., Carpenter, K. J. \& Woodham, A. A. (1961). F. Sci. Fd Agric. 12, 832.

Bressani, R. \& Elias, L. G. (1968). Adv. Fd Res. 16, r.

Bressani, R. \& Scrimshaw, N. S. (г961). Publs natn. Res. Coun., Wash. no. 843, p. 35.

Campbell, J. A. (1963). Methodology of Protein Evaluation, Publ. No. 21, p. 21. Beirut, Lebanon: American University of Beirut.

Carpenter, K. J. \& Woodham, A. A. (1974). Br. Y. Nutr. 32, 647.

FAO (1965). FAO Nutr. Mtg Rep. Ser. No. 37.

Grau, C. R. \& Almquist, H. J. (I944). Proc. Soc, exp. Biol. Med. 57, 187.

Matheson, N. A. (1974). Br. F. Nutr. 31, 393.

Moore, S. (I963). F. biol. Chem. 238, 235.

Oser, B. L. (195I). J. Am. Diet. Ass. 27, 396.

Spackman, D. H., Stein, W. H. \& Moore, S. (1958). Analyt. Chem. 30, I 190.

Spies, J. R. \& Chambers, D. C. (1949). Analyt. Chem. 21, I249.

Thomas, O. P., Martin, R. S., Wessels, J. P. H. \& Human, J. B. B. (1965). S. Afr. F. agric. Sci. 8, 1061. 
UN Protein Advisory Group (1974). PAG Bull, 4, no. 3, p. I7.

Winburne, J. N. (1962). Dictionary Agriculture and Applied Terminology. p. 787. Michigan State University Press.

Woodham, A. A. (1968). Br. Poult. Sci. 9, 53.

Woodham, A. A. \& Deans, P. S. (1973). Br. Poult. Sci. 14, 569.

Woodham, A. A. \& Deans, P. S. (1975). Br. Poult. Sci. 16, 269-287. 